\title{
a-Linolenic Acid Induces Breast Cancer Cell Apoptosis by Down-Regulating Human Fatty Acid Synthase
}

\section{Wenyuan Huang}

University of Chinese Academy of Sciences School of Computer and Control Engineering: University of the Chinese Academy of Sciences School of Computer Science and Technology

\section{Xing Guo}

University of the Chinese Academy of Sciences

\section{Huijin Fan}

University of Chinese Academy of Sciences

\section{Amantay Alzhan}

University of the Chinese Academy of Sciences

\section{Zhengan Liu}

Institute of Botany Chinese Academy of Sciences

\section{Xiaofeng Ma ( $\square$ maxiaofeng@ucas.ac.cn )}

University of the Chinese Academy of Sciences https://orcid.org/0000-0001-9834-5477

\section{Qingyan Shu}

Institute of Botany Chinese Academy of Sciences

\section{Research Article}

Keywords: Fatty acid synthase, a-Linolenic acid, Inhibitor, Breast cancer cells, Cell apoptosis.

Posted Date: April 5th, 2021

DOI: https://doi.org/10.21203/rs.3.rs-344421/v1

License: (c) (1) This work is licensed under a Creative Commons Attribution 4.0 International License. Read Full License 


\author{
Wenyuan Huang ${ }^{\mathrm{a}}$ \\ huangwenyuan16@mails.ucas.ac.cn \\ Xing $\mathrm{Guo}^{\mathrm{a}}$ \\ guoxing19@mails.ucas.ac.cn \\ Huijin Fan ${ }^{b}$ \\ fanhuijin19@mails.ucas.ac.cn \\ Amantay Alzhan ${ }^{\mathrm{a}}$ \\ alzhan.zh@mail.ru \\ Zhengan $\mathrm{Liu}^{\mathrm{c}}$ \\ liuzhengan@ibcas.ac.cn \\ Xiaofeng $\mathrm{Ma}^{\mathrm{a}, *}$ \\ maxiaofeng@ucas.ac.cn \\ Qingyan $\mathrm{Shu}^{\mathrm{c}, *}$ \\ shuqy@ibcas.ac.cn
}

${ }^{a}$ College of Life Sciences, University of Chinese Academy of Sciences, No. 19A Yuquan Road, Beijing 100049, China

${ }^{\mathrm{b}}$ Medical College, University of Chinese Academy of Sciences, No. 19A Yuquan Road, Beijing 100049, China

${ }^{\mathrm{c}}$ Key Laboratory of Plant Resources and Beijing Botanical Garden, Institute of Botany, the Chinese Academy of Sciences, Beijing 100093, China

* Corresponding author.

Qingyan Shu, Ph. D, Associate Professor, Key Laboratory of Plant Resources and Beijing Botanical Garden, Institute of Botany, the Chinese Academy of Sciences, Beijing 100093, China; Email: shuqy@ibcas.ac.cn; Tel. /Fax: +8610-62836655

Xiaofeng Ma, Ph. D, Associate Professor, College of Life Sciences, University of Chinese Academy of Sciences, No. 19A Yuquan Road, Beijing 100049, China; Email: maxiaofeng@ucas.ac.cn; Tel. /Fax:

$+8610-88256585$ 


\section{Abstract}

Background/Aims: Fatty acid synthase (FASN) is a multi-enzyme complex that synthesizes endogenous fatty acids. The overexpression of FASN has been reported in variety of cancers, including breast, ovarian, prostrate, and colon cancers, which strongly indicates the involvement of FASN in cancer progression. $\alpha$-Linolenic acid (ALA) has many biological activities, including anti-cancer effects. The aim of the present study was to investigate the inhibitory effect of ALA on fatty acid synthesis pathway and apoptosis of human breast cancer cells.

Methods: Cytotoxicity of ALA in human breast cancer cells (MDA-MB-231 and MCF-7 cells) was assessed by MTT assay. Changes in protein expression were detected by immunoblot analysis. Cell migration was detected by wound healing and cell transwell assay. Apoptotic effects, mitochondrial membrane potential and cell cycle analysis were detected by flow cytometry. Molecular docking was carried out with the AutoDockTools program suite to analyze the binding abilities of ALA on thioesterase (TE) domain of FASN.

Results: We found that the expression levels of FASN decreased significantly in ALA treated breast cancer cells. Compared with palmitic acid (PA), ALA reduced cell viability in a dose-dependent manner. ALA showed a higher affinity with the TE domain than PA. ALA induced breast cancer cells apoptosis, which effects were similar with the knockdown of FASN. In addition, ALA inhibited the invasion and metastasis, and arrested cell cycle in breast cancer cells.

Conclusion: We propose a hypothesis that ALA could contribute to the treatment of human breast cancer by inhibiting FASN.

Key words: Fatty acid synthase; $\alpha$-Linolenic acid; Inhibitor; Breast cancer cells; Cell apoptosis. 


\section{Background}

Breast cancer is one of the most serious diseases to threaten female's health [1]. Although some of them who suffered from breast cancer could be cured, however, there are lots of people has poor prognosis which leading to death [2]. It has high risk to invade other tissues and organs. Breast cancer invasion and metastasis are the main reasons to cause of patient's death $[3,4]$. Until now, plenty of drugs have been developed to treat breast cancer, however breast cancer remains a complex health problem for woman around the world [5]. Therefore, development of effective drug to treat breast cancer is an urgent need.

Many researches have explored that fatty acid synthase (FASN, EC 2.1.3.85) expression in breast cancer cell various from normal to overexpressed in cancer cell $[6,7]$. High levels of FASN expression and activity provide favorable conditions for tumor growth and progression $[8,9]$. FASN is considered as a marker of poor prognosis [10]. FASN is an enzyme that catalyzes the synthesis of long-chain fatty acid using acetyl-coenzyme A (CoA), malonyl-CoA, and NADPH as its substrates [9]. As the only enzyme that endogenously synthesizes fatty acids in cells, FASN plays a vital role in cell growth. Fatty acids are irreplaceable factors in cell growth and important parts of cell membranes. In addition, some intermediate fatty acids metabolites could directly stimulate cell growth [11]. Previous study revealed that $93 \%$ of the fatty acids which consumed by cancer cells are catalyzed by FASN, meanwhile the main fatty acids which used by normal cells come from diets [12]. Since FASN plays an essential role in breast cancer and it is totally contrasting between normal cells and cancer cells, FASN is considered as a new target. It has been identified that inhibiting FASN could induce cancer cell apoptosis, but the mechanism remains to be studied [13, 14]. Palmitic acid (PA), the main product of FASN catalyzed reaction, is reduced after inhibition of FASN, which then leads to apoptosis of cancer cells [15]. Malonyl-CoA will be accumulated after the suppression of FASN. Excess malonyl-CoA will repress acylcarnitine transferase 1, and the apoptosis pathway will be triggered [16]. Many studies have illustrated the relationship between FASN and 
molecular pathway signaling, such as P53 pathway PI3K-AKT and MAPK etc. [17, 18]. Therefore, the discovery of FASN inhibitors would bring new opportunity for metabolically combating cancer.

$\alpha$-Linolenic acid (ALA) is a long chain fatty acid with 18 carbon and three cis double bonds. Most of the ALA comes from plant seeds, especially from flax and peony seeds. ALA is an essential fatty acid for human being but cannot be synthesized by the human body [19]. ALA assists human to keep health by direct and indirect way. If there is a lack of ALA in the diet, the person may suffer from chronic diseases such as obesity, atherosclerosis and cardiovascular disease [20,21]. ALA can improve leptin levels and decrease epididymal adiposity, as well as adipocyte size in mice [22]. ALA administration prevents diabetes and its complications via PI3K/AKT signaling [23]. Besides, many studies indicate that ALA exerts anti-inflammatory and antioxidant effects through increasing the expression level of Nrf2 [24, 25]. In addition, ALA transforms other biological substances such as DHA and EPA, as a precursor. These biological molecules could contribute to the metabolism of saturated fatty acids, which reduces the risk of atherosclerosis [26]. Recently, more and more evidence prove that ALA has an anti-cancer effect, but the mechanism remains unknown [27, 28].

Since ALA could reduce adipose tissue size and induce cancer cell apoptosis, meanwhile FASN plays a significant role in fat synthesis and cancer, therefore it is proposed that ALA induces apoptosis of breast cancer cell by inhibiting FASN. To investigate whether ALA-mediated cancer cell apoptosis is related to FASN, firstly, the effect of ALA on FASN expression in breast cancer cells was tested. Cytotoxicity of ALA was explored, subsequently, we detected whether ALA affects breast cancer cell invasion and metastasis. The discovery of ALA as a new FASN inhibitor will provide one of the potential perspective anticancer treatments.

\section{Methods}

\section{Reagents}


USA). RPMI 1640 Medium basic and phosphate-buffered saline (PBS) were purchased from Biological Industries (Israel). Fetal bovine serum (FBS) was purchased from South America sterile filtered. Antibodies of FASN, IRE1, ATF6, PERK, and CHOP were purchased from Cell Signaling Technology (Denvers, MA, USA).

GAPDH was purchased from Lablead (Beijing, China).

105

\section{Cell lines and culture}

The human breast cancer cell lines MDA-MB-231 and MCF-7 cells were purchased from the Type Culture Collection of the Chinese Academy of Sciences, Shanghai, China. Cells were grown in DMEM, supplemented with $10 \% \mathrm{FBS}$ and were maintained in a humidified atmosphere containing $95 \%$ air and $5 \% \mathrm{CO}_{2}$ at $37{ }^{\circ} \mathrm{C}$.

\section{Cell viability assay}

Cell viability assays were performed in 96-well plates. MDA-MB-231 and MCF-7 cells were cultured in the plates until confluence and were incubated with either DMSO (1:1000) or increasing doses of ALA for $24 \mathrm{~h}$ at $37{ }^{\circ} \mathrm{C}$. Cell medium was then changed to a fresh one within $500 \mu \mathrm{g} / \mathrm{mL}$ MTT. After $4 \mathrm{~h}$ incubation at $37^{\circ} \mathrm{C}$, the plates were decanted and added $150 \mu \mathrm{L}$ DMSO to solubilize the formazan crystals. The plate was analyzed by a microplate spectrophotometer (Multiskan, MK3) at the wavelength of $492 \mathrm{~nm}$. All experiments were carried out five times on three different occasions.

\section{Analysis of apoptosis}

At $24 \mathrm{~h}$ after ALA treatment, the cells were collected and washed twice with cold PBS, and then resuspended at a density of $1 \times 10^{6}$ cells per $\mathrm{mL}$. The cell suspension $(500 \mu \mathrm{L})$ was incubated with Annexin-V-FITC $(5 \mu \mathrm{L})$ and PI $(10 \mu \mathrm{L})$ for 15 min in dark, and analyzed with FACScalibur instrument (Becton-Dickinson, San Jose, US) within $1 \mathrm{~h}$.

\section{Western blot analysis}



collected using trypsin-EDTA and washed twice with PBS. Then, a particle free supernatant was obtained by centrifuging at $12,000 \mathrm{~g}$ for $20 \mathrm{~min}$ at $4{ }^{\circ} \mathrm{C}$. The protein concentration of cell lysates was measured by Pierce BCA protein analysis kit. Comparable amounts of protein were separated using a 10\%-12\% SDS-PAGE and transferred to PVDF membranes. Then probed with primary antibodies dilution overnight at $4{ }^{\circ} \mathrm{C}$. After washing thrice with TBST solution, cells were incubated with corresponding secondary antibody for $1 \mathrm{~h}$, and developed with a commercial kit. Western blotting was performed with anti GAPDH antibody to control protein loading and transfer. All experiments were carried out at least three times.

\section{Mitochondrial membrane potential test}

131 The mitochondrial membrane potential $(\Delta \Psi \mathrm{m})$ was detected as described previously [15]. Briefly, after treating with $\operatorname{ALA}(0,25,50,75$, and $100 \mu \mathrm{M})$ for $24 \mathrm{~h}$, cells were digested with trypsin, resuspended at a density of 1 $\times 10^{6}$ cells per $\mathrm{mL}$. After washing thrice with cold PBS, the cells were then stained and incubated with $25 \mu \mathrm{M}$ JC-1 for 30 min at $37^{\circ} \mathrm{C}$. Finally, the fluorescence shift of JC-1 was measured by flow cytometry to evaluate mitochondrial dysfunction.

\section{Immunofluorescence}

137 The FASN expression and distribution in the cell were investigated by immunofluorescence confocal microscopy, after treating with ALA for $24 \mathrm{~h}$, breast cancer cells were planted in the 24-well plate for $12 \mathrm{~h}$. Cultured cells were exposed with various concentrations of ALA for $24 \mathrm{~h}$ and then fixed with $4 \%$ paraformaldehyde for 10 min, PBST was used to wash cells twice, permeabilized with $0.1 \%$ Triton X-100 and

141 then blocked in 3\% BSA for $1 \mathrm{~h}$ at room temperature. Before staining cell nucleus by DAPI for $1 \mathrm{~h}$ without 

CGU GUC ACG UTT) were purchased from GenePharma (Shanghai, China). The siRNA was transfected into cells using Lipofectamine 2000 reagent (Invitrogen) according to the manufacturer's instructions.

\section{Wound healing}

Breast cancer cells were seeded into 6-well plates $\left(2 \times 10^{6}\right.$ cells per well) in DMEM with $10 \%$ FBS overnight. Cells were scratched for a straight line by $200 \mu \mathrm{L}$ pipette tip and then PBS buffer was used to clean cells for three times. DMEM containing different ALA concentrations was used to treat cells for $24 \mathrm{~h}$. The cell migration was observed by microscope.

\section{Cell migration assay}

Transwell assay was applied to measure cell migration. Breast cancer cells were plated in the upper chamber overnight till to an $80 \%$ confluency. Then, different concentrations of ALA were added into DMEM to culture cells at upper chamber while DMEM with 10\% FBS was used in bottom chamber. After $24 \mathrm{~h}$, the upper chamber cell should be removed, migrated cells which appears on under chamber were stained by crystal violet. The results were shown by microscope.

\section{Cell cycle assay}

Cells were seeded in the 6-plates overnight till at a density of $80 \%$. Cells were cleaned three times using PBS to analysis cell cycle by flow cytometry according to the instruction provided by the manufacturer strictly.

\section{Molecular docking}



molecular docking was completed, we clustered analysis of the lowest-energy positions for the inhibitor and then saved the lowest-energy position of the inhibitor in the binding sites of the TE domain.

\section{Statistical analysis}

Data were obtained from the mean \pm standard deviation (SD). One-way analysis of variance (ANOVA) and differences among three or more groups. The statistical significance was at $\mathrm{P}<0.05$ level.

\section{Results}

\section{ALA reduced the cell viabilities of MDA-MB-231 and MCF-7 cells}

To evaluate the cytotoxicity of ALA on human breast cancer cells, MDA-MB-231 and MCF-7 cells were incubated with various concentration of ALA for $24 \mathrm{~h}$. After that, the cell viabilities were detected by MTT assay. ALA treatment for $24 \mathrm{~h}$ decreased breast cancer cell viability in a dose-dependent manner, as shown in the Figure 1. The half inhibition concentration $\left(\mathrm{IC}_{50}\right)$ values of ALA in MDA-MB-231 cells and MCF-7 cells were $45 \mu \mathrm{M}$ and $70 \mu \mathrm{M}$, respectively. These results exhibited that ALA could reduce breast cancer cell viability and suppress cell growth.

\section{ALA induced MDA-MB-231 and MCF-7 cells apoptosis}

In this study, the apoptotic potential for ALA was assessed in both MDA-MB-231 cells and MCF-7 cells using 
$2.9 \%$ to $23.5 \%$ and from 5.5 to $16.7 \%$, respectively) and late (from $0.6 \%$ to $3.4 \%$ and from 2.0 to $13.8 \%$, respectively) apoptotic phases, which involves obvious increase with respect to untreated control cells. We next measured the apoptosis marker proteins PARP and BCL-2. Cells were treated with ALA for $24 \mathrm{~h}$, and then the protein levels were detected by Western blot. As shown in the Figure 2C and 2D, the cleavage PARP increased markedly at $75 \mu \mathrm{M}$ in MCF-7 cells and $100 \mu \mathrm{M}$ in MDA-MB-231 cells. BCL-2, the anti-apoptotic protein, was down-regulated.

\section{ALA inhibited intercellular FASN in MDA-MB-231 and MCF-7 cells}

FASN is concerned to play an important role in breast cancer cell growth. The FASN protein levels were detected by western blot and visualized by immunofluorescence. As shown in the Figure 3A, ALA at a concentration of $80 \mu \mathrm{M}$ down-regulated FASN expression significantly in both MDA-MB-231 and MCF-7 cells. To observe the location of FASN at the cytoplasm, the immunofluorescence technology was applied. Results were shown in the Figure 3B, the green fluorescence weakened gradually with the increased of ALA concentration, it indicated that ALA decreased FASN expression with a dose-dependent pattern.

\section{ALA induced endoplasmic reticulum (ER) stress in MDA-MB-231 cells}

In order to detect the effect of ALA on ER stress, the expression levels of ER stress markers were detected by Western blot. As shown in Figure 4A, ALA administration for $24 \mathrm{~h}$ significantly down-regulated the expression level of FASN, while up-regulated the expression levels of IRE1, ATF6, PERK, and CHOP in MDA-MB-231 cells. To investigate the effect of ALA on mitochondria, mitochondrial membrane potential was measured after ALA treatment. As shown in Figure 4B and 4C, ALA decreased the mitochondrial membrane potential of both MDA-MB-231 cells and MCF-7 cells.

\section{FASN knockdown induced ER stress and decreased cell viability}

To identify whether the cell viability and ER stress were related with FASN expression in the breast cancer cells, 


\section{The cell viability and FASN expression were decreased by ALA rather than PA}

In order to confirm whether the effect of ALA on cell viability and FASN expression level is specific, we

\section{Acetyl-CoA carboxylase inhibition enhanced the cytotoxicity of ALA}

For FASN synthesized reaction, acetyl-CoA, malonyl-CoA, and NADPH are applied to product palmitic acid. 

cell invasion was inhibited significantly. The cell invasion was almost completely suppressed by $75 \mu \mathrm{M}$ ALA. Cell metastasis was measured by transwell assay. Incubation MDA-MB-231 cells with ALA for $24 \mathrm{~h}$, resulted in a dose-dependent inhibition of MDA-MB-231 cells metastasis ability (Figure 8B). continues to increase, the proportion of cells in the second peak (G2 phase) decreased. Therefore, ALA could significantly inhibit cell cycle from G2 phase to S phase.

\section{Acetyl-CoA, and malonyl-CoA were not affected after treating with ALA} acetyl-CoA, malonyl-CoA, and NADPH concentrations were measured by corresponding kits (Acetyl-CoA kit, Malonyl-CoA kit, and NADPH kit). The result showed that ALA treatment could not increase or decrease the concentrations of both acetyl-CoA and malonyl-CoA.

\section{ALA showed higher affinity with the TE domain than PA}

To evaluate the affinity of ALA with TE domain (one of FASN domain). We calculated the binding energy that

ALA and PA with TE respectively. Results were shown as the Figure 10A. ALA occupies hydrophobic pocket

A and forms a broad hydrophobic interaction with GLU2366, TYR2351, LEU24277, PHE2370, PHE2423,

ILE2250, TYR2309 and VAL2344. In addition, the carboxyl group of the ALA forms a salt bridge with the guanidyl groups of ARG2352 and ARG2428. Ser2308-His2481-Asp2338 catalytic triad does not contribute to the binding of ALA. Thus, the primary driving force for the binding of ALA to the TE domain is electrostatic interactions and hydrophobic interactions. 


\section{Discussion}

Fatty acids are important sources of energy production and structural components of cells, and also important regulators of gene expression by interacting with various transcription factors. Intake of different types of fatty acids, as well as the total amount of fat, will cause metabolic changes. ALA is an essential omega-3 fatty acid needed for human health. Essential fatty acids are thought to affect several metabolic processes, including regulation of energy supply, enzyme activity and gene expression. Therefore, it is believed that the decrease or imbalance of these lipid levels will have a pathogenic effect on many human diseases. In particular, a large amount of evidence suggests that ALA intake is negatively correlated with coronary and carotid atherosclerotic diseases, and is associated with neuroprotective, antidepressant and antidepressant effects. Many biological functions of ALA have been reported, including cardiovascular protection, neuroprotection, anti-cancer, antiosteoporosis, anti-inflammatory and antioxidant effects [29]. However, the detailed mechanisms involved remain unclear. In the present study, we proved that ALA could reduce survival rate, induce apoptosis, inhibit cell invasion and metastasis, and block cell cycle in human breast cancer cells.

To gain further insight into the mechanism underlying the anti-cancer effect of ALA, the effect of ALA on

271 intracellular FASN was investigated. Lots of studies proved that ALA could reduce fat accumulation and keep body slim, which provided evidence that ALA could affect fatty acid metabolism [30]. Coincidentally, FASN is

273 a dual target of anti-obesity and anti-cancer [31]. In this study, we found that ALA could down-regulate the expression level of FASN. ALA exhibited higher binding ability to the TE domain of FASN than PA. In order 
expression in breast cancer cells. The viability of breast cancer cells decreased significantly after the expression of FASN was down-regulated, which was similar to that of ALA treatment. Therefore, ALA may reduce breast cancer cells viability through inhibiting FASN.

ER has multiple functions, especially in the synthesis, folding, modification, and transportation. Several enzymes related to lipid metabolism are located in the ER $[32,33]$. The ER homeostasis will be destroyed after cells are stimulated, for maintain the balance of microenvironment, apoptosis procedure will be triggered [34]. According to our results, the ER stress related proteins were up-regulated, which means ER stress was activated by both ALA treatment and FASN knocking down. The change of ER stress markers is an important mean to reflect mitochondrial stress. We also investigated the effect of ALA on mitochondria. The results showed that ALA induces mitochondrial stress or injury. ER stress response is essential for the survival of cancer cells under some circumstances. However, long-term ER stress and UPR pathway activation can lead to apoptosis. In this study, we found that ALA induced both ER stress and mitochondrial membrane potential reduction. It is strongly suggested that ER stress was involved in ALA induced breast cancer cell death.

FASN substrates accumulation should be considered for breast cancer cell apoptosis while FASN was inhibited. NADPH and malonyl-CoA have been reported the apoptosis effect on cancer cells. Excess malonyl-CoA has cytotoxicity for cancer cells. Malonyl-CoA was produced by acetyl-CoA carboxylase and consumed by FASN, malonyl-CoA will be accumulated due to the inhibition of FASN. CPT1 will be inhibited by excess malonylCoA, which could trigger apoptosis procedure $[35,36]$. We aim to identify whether ALA could induce apoptosis via this way. Acetyl-CoA carboxylase was suppressed by TOFA to decreased the accumulation of malonyl-CoA. According to previous study, cell viability will be remedy by TOFA after inhibiting FASN. One unanticipated 
not statistically significant. A series of experiments show that ALA induced breast cancer cell apoptosis by inhibiting FASN independent malonyl-CoA accumulation. Besides, acetyl-CoA and NADPH also were explored by measuring its concentrations, the result did not present significant difference.

Consistent with the previous research, we found that ALA can also block cell cycle, inhibit the invasion and metastasis of tumor cells [37]. These results prove that ALA can inhibit the development of tumor cells. This also provides a theoretical basis for the development of ALA as an anti-tumor drug or an anti-tumor adjuvant drug. At the same time, it also reminds people that the proper addition of ALA in daily diet is very helpful for maintaining good health. Although we demonstrated the mechanism of ALA induced cancer cell apoptosis, this study remains some limitation. Further animal experiments are urgently needed to determine the feasibility of ALA as an anticancer drug.

\section{Conclusions} apoptosis via inhibiting FASN.

\section{Declarations}

\section{Authors' contributions}

$\mathrm{XM}$, as the principal investigator, was responsible for the concept and design of the study.

WH, XG, HF, AA, XM, QS, ZL conducted the research and wrote the manuscript.

WH, XG, HF, AA did the whole experiments of the study.

\section{Acknowledgements}




\section{Ethics approval and consent to participate}

no human subjects.

\section{Consent for publication}

324 Not applicable, no human subjects.

\section{Availability of data and material}

All data analyzed and generated during the current study are available from the corresponding author upon reasonable request.

\section{Funding}

This work was supported by the Strategic Priority Research Program of the Chinese Academy of Sciences

\section{Competing interests}

The authors declare that they have no competing interests.

\section{Disclosure Statement}

336 The authors declare no conflicts of interest. 


\section{References}

340 1. Fan L, Strasser-Weippl K, Li JJ, St Louis J, Finkelstein DM, Yu KD, Chen WQ, Shao ZM, Goss PE. Breast cancer in China. Lancet Oncol 2014; 15:e279-89.

2. Peart O. Breast intervention and breast cancer treatment options. Radiol Technol 2015; 86:535M-58M; quiz $59-62$.

3. Davies K. The Complex Interaction of Matrix Metalloproteinases in the Migration of Cancer Cells through Breast Tissue Stroma. Int J Breast Cancer 2014; 2014:839094.

4. Westcott JM, Prechtl AM, Maine EA, Dang TT, Esparza MA, Sun H, Zhou Y, Xie Y, Pearson GW. An epigenetically distinct breast cancer cell subpopulation promotes collective invasion. J Clin Invest 2015;

5. Fisusi FA, Akala EO. Drug combinations in breast cancer therapy. Pharmaceutical Nanotechnology 2019; $7: 3-23$

6. Menendez JA, Lupu R. Fatty acid synthase and the lipogenic phenotype in cancer pathogenesis. Nat Rev Cancer 2007; 7:763-77.

7. Menendez JA, Lupu R. Fatty acid synthase (FASN) as a therapeutic target in breast cancer. Expert Opin Ther Tar 2017; 21:1001-16.

8. Jones SF, Infante JR. Molecular pathways: fatty acid synthase. Clin Cancer Res 2015; 21:5434-8. Med Chem Lett 2015; 25:4363-9. $32: 391$ 
11. Papaevangelou E, Almeida GS, Box C, deSouza NM, Chung YL. The effect of FASN inhibition on the growth and metabolism of a cisplatin-resistant ovarian carcinoma model. Int J Cancer 2018; 143:992-1002.

12. Ookhtens M, Kannan R, Lyon I, Baker N. Liver and adipose tissue contributions to newly formed fatty acids in an ascites tumor. Am J Physiol 1984; 247:R146-53.

13. Li P, Tian W, Ma X. Alpha-mangostin inhibits intracellular fatty acid synthase and induces apoptosis in breast cancer cells. Mol Cancer 2014; 13:138.

14. Ventura R, Mordec K, Waszczuk J, Wang Z, Lai J, Fridlib M, Buckley D, Kemble G, Heuer TS. Inhibition $2015 ; 2: 808-24$

15. Huang W, Liang Y, Ma X. Alpha-mangostin induces endoplasmic reticulum stress and autophagy which

16. Puig T, Vázquez-Martín A, Relat J, Pétriz J, Menéndez JA, Porta R, Casals G, Marrero PF, Haro D, Brunet count against fatty acid synthase inhibition mediated apoptosis in human breast cancer cells. Cancer Cell Int 2019; 19:151.

J, Colomer R. Fatty acid metabolism in breast cancer cells: differential inhibitory effects of epigallocatechin gallate (EGCG) and C75. Breast Cancer Res Tr 2008; 109:471-9.

17. Jiang Y, Yin X, Wu L, Qin Q, Xu J. MAPK/P53-mediated FASN expression in bone tumors. Oncol Lett $2017 ; 13: 4035-8$.

18. Li N, Bu X, Wu P, Wu P, Huang P. The "HER2-PI3K/Akt-FASN Axis" regulated malignant phenotype of colorectal cancer cells. Lipids 2012; 47:403-11.

19. Kim KB, Nam YA, Kim HS, Hayes AW, Lee BM. $\alpha$-Linolenic acid: nutraceutical, pharmacological and toxicological evaluation. Food Chem Toxicol 2014; 70:163-78. 
20. Zhuang P, Shou Q, Wang W, He L, Wang J, Chen J, Zhang Y, Jiao J. Essential fatty acids linoleic acid and $\alpha$-linolenic acid sex-dependently regulate glucose homeostasis in obesity. Mol Nutr Food Res 2018; 62:e1800448.

21. Egert S, Baxheinrich A, Lee-Barkey YH, Tschoepe D, Stehle P, Stratmann B, Wahrburg U. Effects of a hypoenergetic diet rich in $\alpha$-linolenic acid on fatty acid composition of serum phospholipids in overweight and obese patients with metabolic syndrome. Nutrition 2018; 49:74-80.

22. Zhou X, Wu W, Chen J, Wang X, Wang Y. AMP-activated protein kinase is required for the anti-adipogenic effects of alpha-linolenic acid. Nutr Metab 2015; 12:10.

23. Zhang W, Wang R, Han SF, Bu L, Wang SW, Ma H, Jia GL. Alpha-linolenic acid attenuates high glucoseinduced apoptosis in cultured human umbilical vein endothelial cells via PI3K/Akt/eNOS pathway. Nutrition 2007; 23:762-70.

24. Zeng YY, Jiang WD, Liu Y, Wu P, Zhao J, Jiang J, Kuang SY, Tang L, Tang WN, Zhang YA, Zhou XQ, Feng L. Dietary alpha-linolenic acid/linoleic acid ratios modulate intestinal immunity, tight junctions, antioxidant status and mRNA levels of NF-kB p65, MLCK and Nrf2 in juvenile grass carp (Ctenopharyngodon idella). Fish Shellfish Immunol 2016; 51:351-64.

25. Wang XH, Cui XX, Sun XQ, Wang XH, Li XC, Qi Y, Li W, Han MY, Muhammad I, Zhang XY. High fat diet-induced hepatic 18-carbon fatty acids accumulation up-regulates CYP2A5/CYP2A6 via NF-E2related factor 2. Front Pharmacol 2017; 8:233.

26. Bavelaar FJ, Beynen AC. Severity of atherosclerosis in parrots in relation to the intake of alpha-linolenic acid. Avian Dis 2003; 47:566-77.

27. Gutierrez-Pajares JL, Ben Hassen C, Oger C, Galano JM, Durand T, Frank PG. Oxidized products of $\alpha$ linolenic acid negatively regulate cellular survival and motility of breast cancer cells. Biomolecules 2019; 
28. Mason JK, Klaire S, Kharotia S, Wiggins AK, Thompson LU. $\alpha$-linolenic acid and docosahexaenoic acid, alone and combined with trastuzumab, reduce HER2-overexpressing breast cancer cell growth but differentially regulate HER2 signaling pathways. Lipids Health Dis 2015; 14:91.

29. Wiggins AK, Mason JK, Thompson LU. Growth and gene expression differ over time in alpha-linolenic acid treated breast cancer cells. Exper Cell Res 2015; 333:147-54.

30. Perng W, Villamor E, Mora-Plazas M, Marin C, Baylin A. Alpha-linolenic acid (ALA) is inversely related to development of adiposity in school-age children. Eur J Clin Nutr 2015; 69:167-72.

31. Wu X, Qin L, Fako V, Zhang JT. Molecular mechanisms of fatty acid synthase (FASN)-mediated resistance to anti-cancer treatments. Adv Biol Regul 2014; 54:214-21.

32. Schwarz DS, Blower MD. The endoplasmic reticulum: structure, function and response to cellular signaling. Cell Mol Life Sci 2016; 73:79-94.

33. Suzuki M. Regulation of lipid metabolism via a connection between the endoplasmic reticulum and lipid droplets. Anat Sci Int 2017; 92:50-4.

34. Fernández A, Ordóñez R, Reiter RJ, González-Gallego J, Mauriz JL. Melatonin and endoplasmic reticulum stress: relation to autophagy and apoptosis. J Pineal Res 2015; 59:292-307.

35. Zhou W, Tu Y, Simpson PJ, Kuhajda FP. Malonyl-CoA decarboxylase inhibition is selectively cytotoxic to human breast cancer cells. Oncogene 2009; 28:2979-87.

36. Thupari JN, Pinn ML, Kuhajda FP. Fatty acid synthase inhibition in human breast cancer cells leads to malonyl-CoA-induced inhibition of fatty acid oxidation and cytotoxicity. Biochem Biophys Res Commun $2001 ; 285: 217-23$. 
Figure 1. Effect of ALA on breast cancer cell viabilities.

A

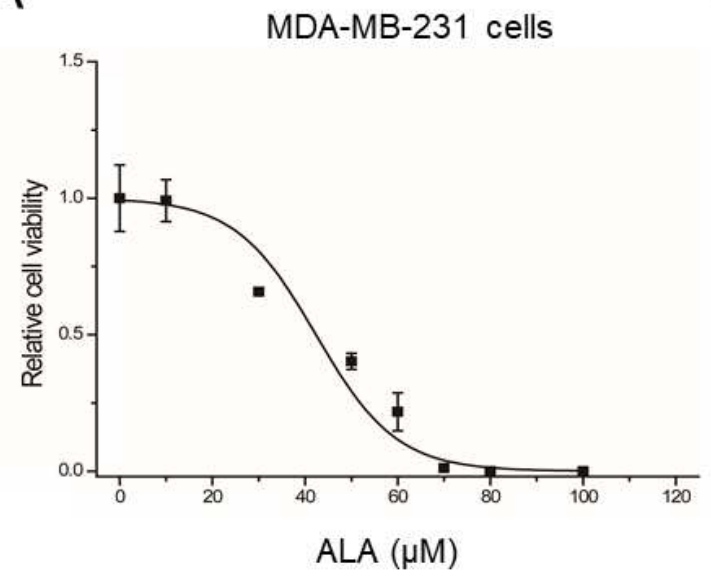

B

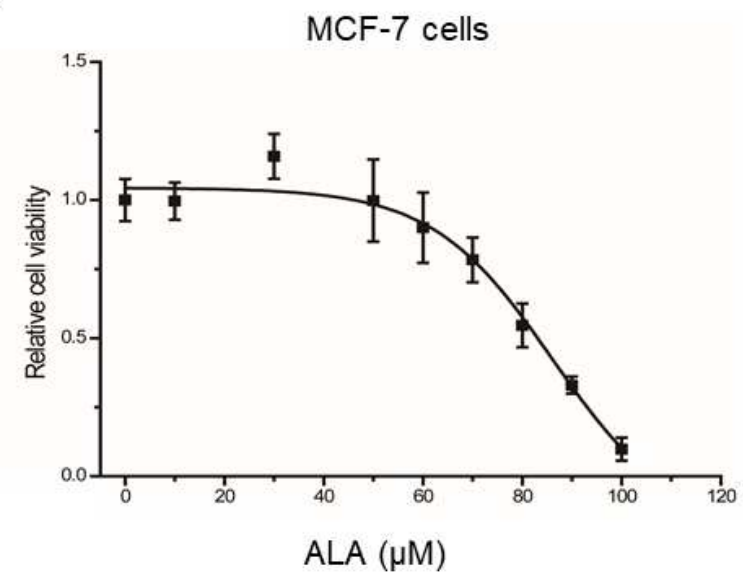

Figure 2. Apoptotic effect of ALA on MCF-7 and MDA-MB-231 cells.

(A) MDA-MB-231 cells and MCF-7 cells were treated with various concentrations of ALA for $24 \mathrm{~h}$, then control. 
A
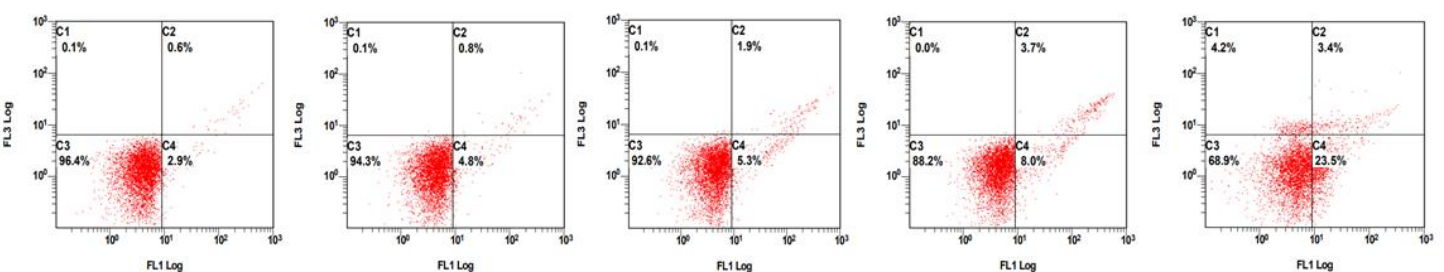

MDA-MB-231 cells

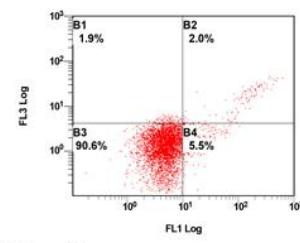

MCF-7 cells

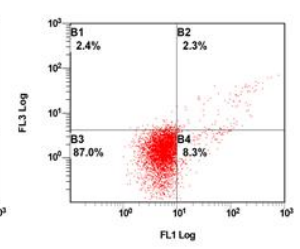

25

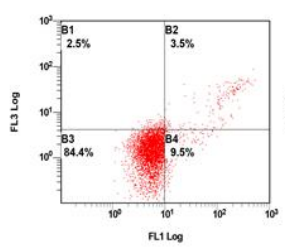

50

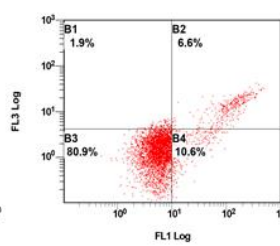

75

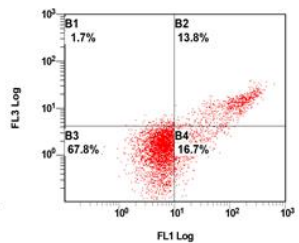

100 ALA $(\mu \mathrm{M})$

B

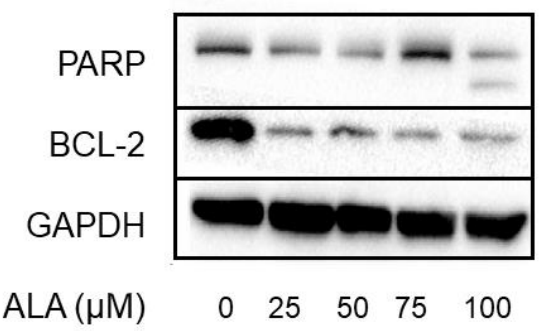

Figure 3. ALA down-regulated intercellular FASN expression in breast cancer cells.

(A) The expression levels of FASN after ALA treatment for $24 \mathrm{~h}$ in MDA-MB-231 and MCF-7 cells were detected. FASN was stained by FASN antibody with FITC (green fluorescence), nucleus was stained by DAPI (blue fluorescence). The image was analyzed by fluorescence microscope. (B) The expression levels of FASN were analyzed by western blot after ALA treatment. 
A

449

450

451

452

453

454

455

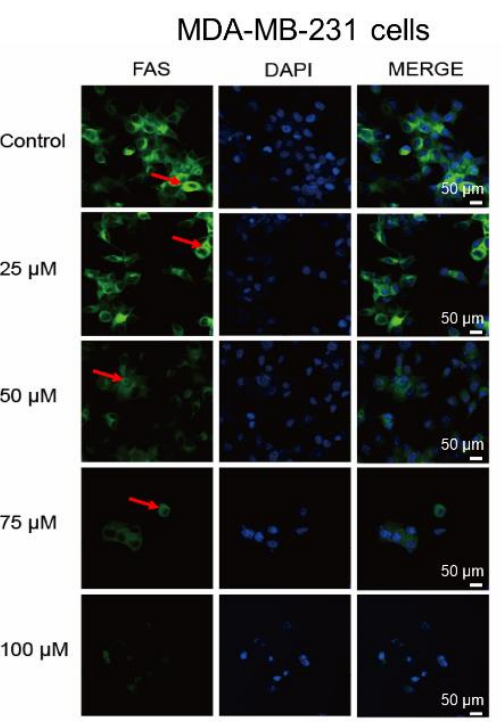

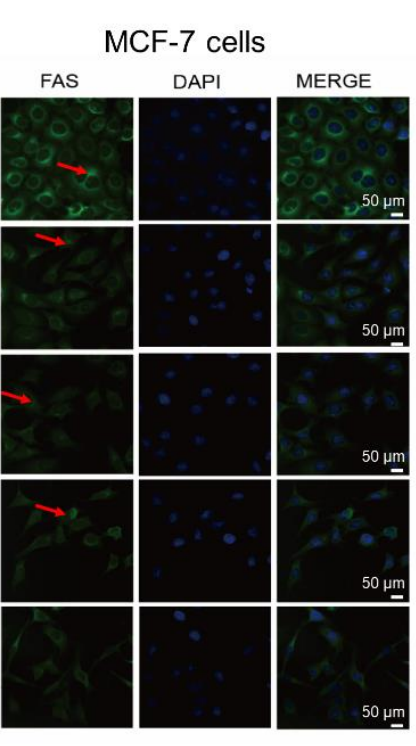

B

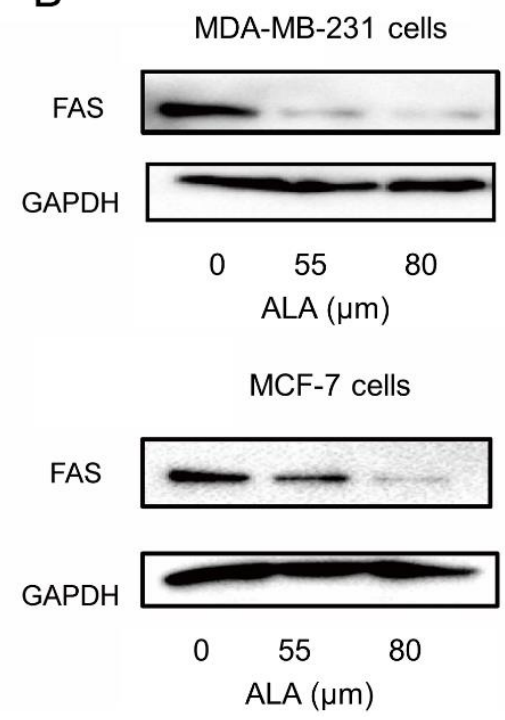

Figure 4. The effects of ALA on ER stress in MDA-MB-231 cells.

(A) At $24 \mathrm{~h}$ after ALA $(100 \mu \mathrm{M})$ treatment, the relative expression levels of FASN, ATF6, IRE1, PERK, and CHOP were analyzed by western blot. (B) MDA-MB-231 cells and (C) MCF-7 cells were treated with ALA (0, $25,50,75$, and $100 \mu \mathrm{M}$ ) analyzed by measuring the fluorescence shift of JC-1 with a flow cytometer to assess the mitochondrial dysfunction.

A

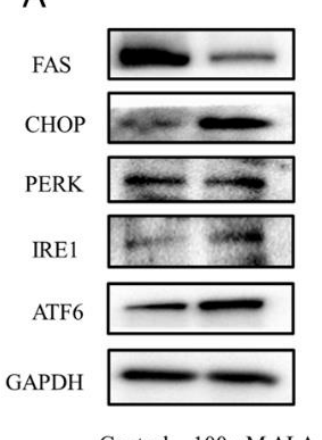

Control $100 \mu \mathrm{M}$ ALA
B
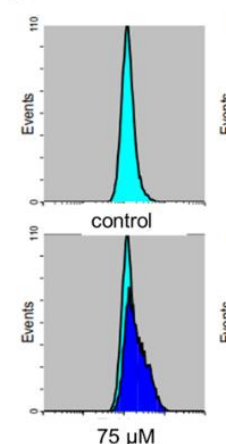
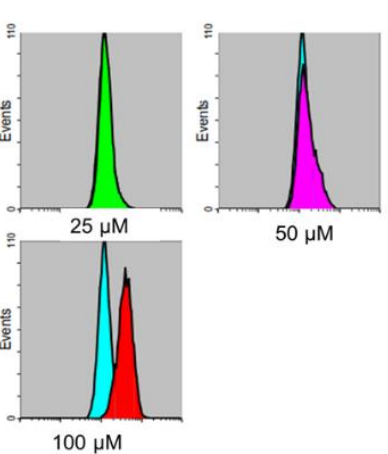

C
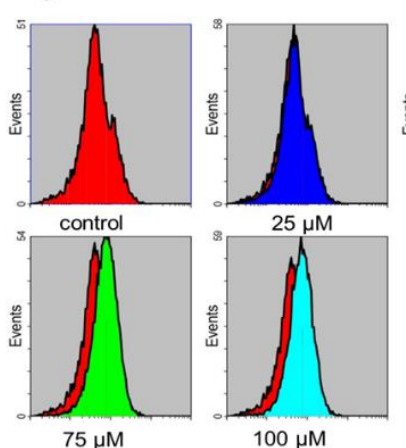

$100 \mu \mathrm{M}$

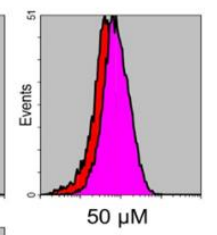

Figure 5. Down-regulating FASN expression reduced cell viability and induced ER stress in MDA-MB-

231 cells.

(A) MDA-MB-231 cells were transfected with FASN targeted siRNA for $24 \mathrm{~h}$. The survival rate of cells was 

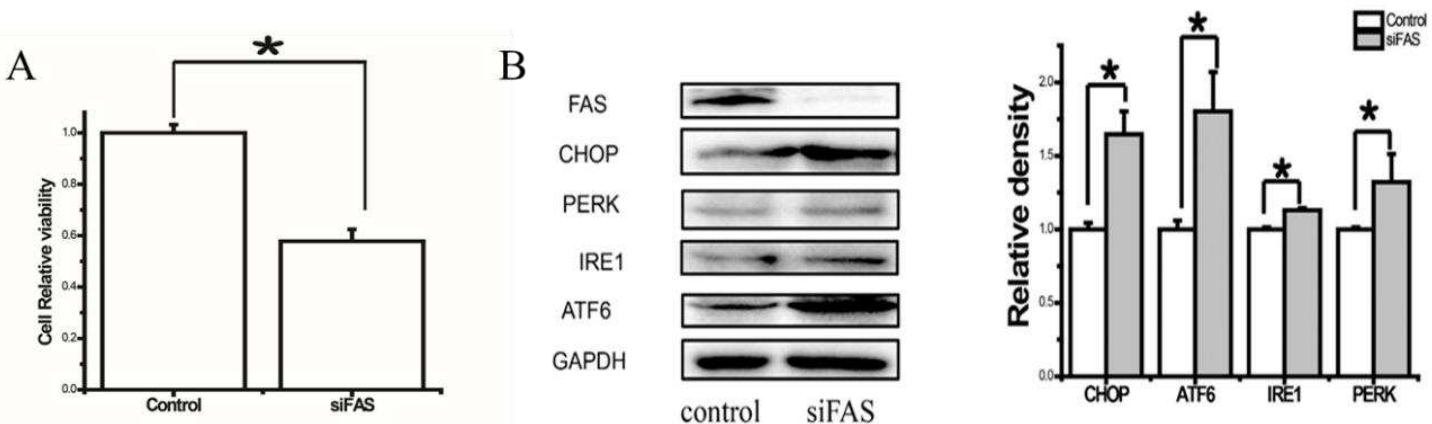

Figure 6. The effects of ALA, PA on cell viability and FASN expression level in breast cancer cells.

Various concentration of ALA or PA $(0,25,50,70$, and $100 \mu \mathrm{M})$ treated MDA-MB-231 cells (A) and MCF-7

A

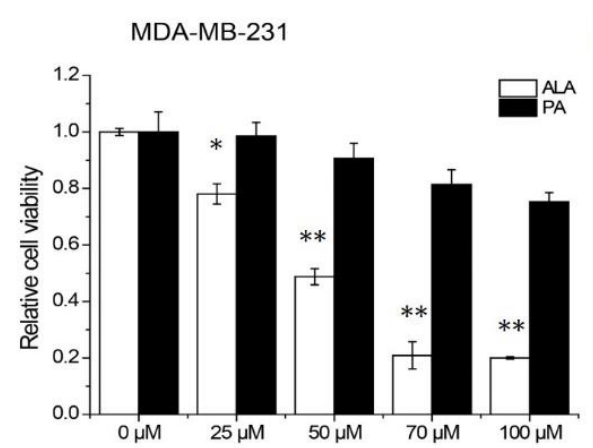

$\mathrm{C}$

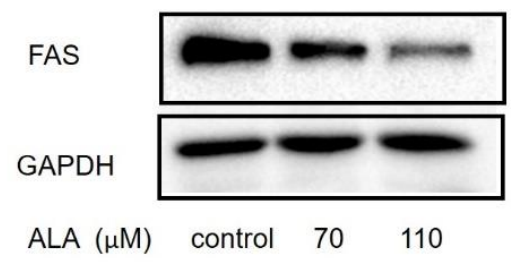

B

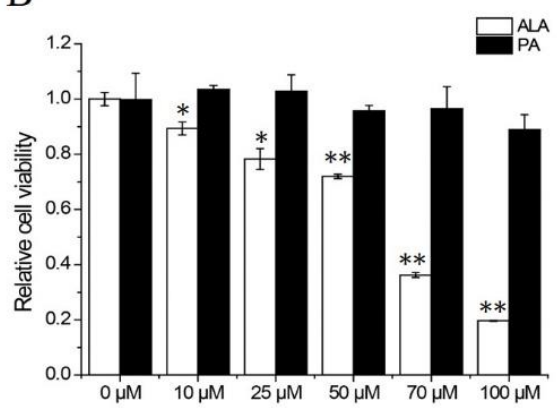

$\mathrm{D}$

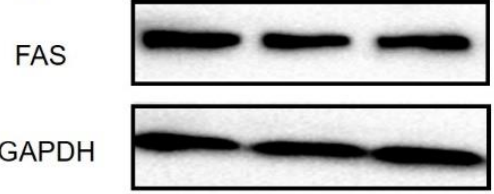

$\mathrm{PA}(\mu \mathrm{M}) \quad$ control $70 \quad 110$

Figure 7. The effects of ALA and TOFA on cell viability in breast cancer cells. 
472 cell viabilities were measured by MTT assay. $* \mathrm{p}<0.05, * * \mathrm{p}<0.01$.

MDA-MB-231 cells

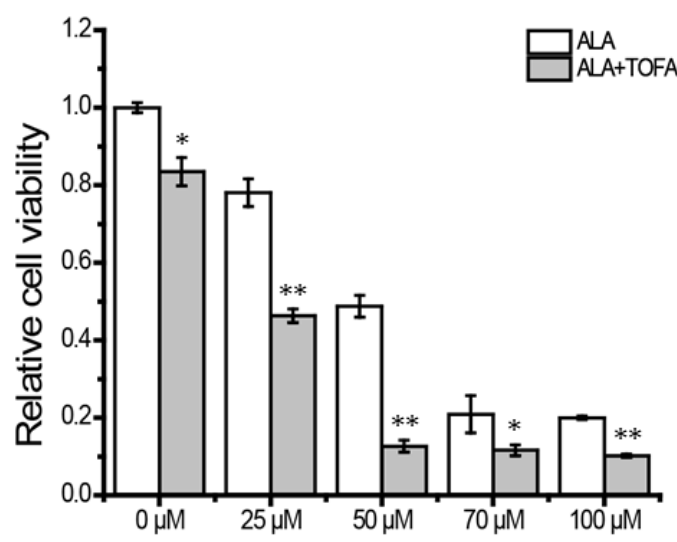

MCF-7 cells

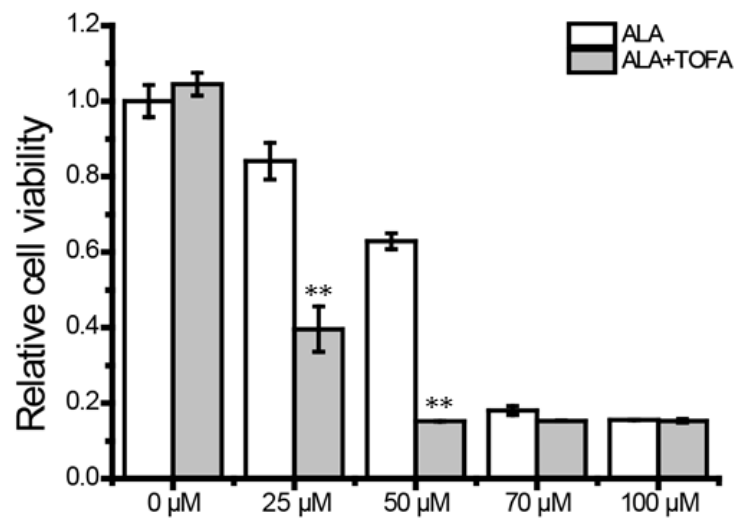

Figure 8. ALA inhibited the invasion and arrested the cell cycle of MDA-MB-231 cells.

(B) Transwell assay. (C) Cell cycles were analyzed. 


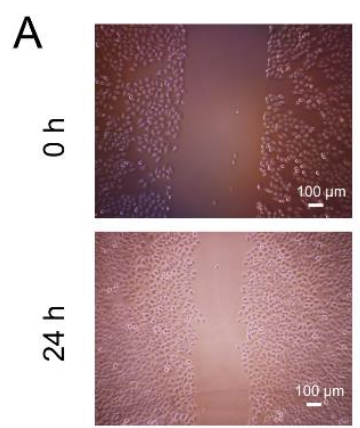

0

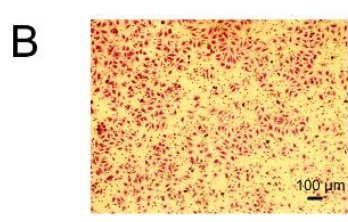

0

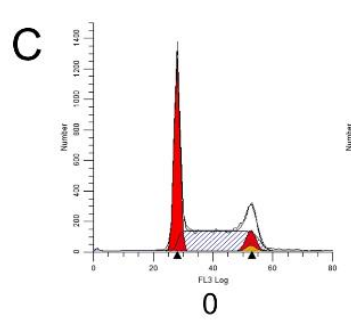

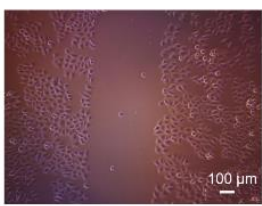

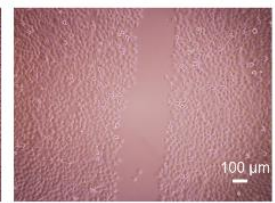

25
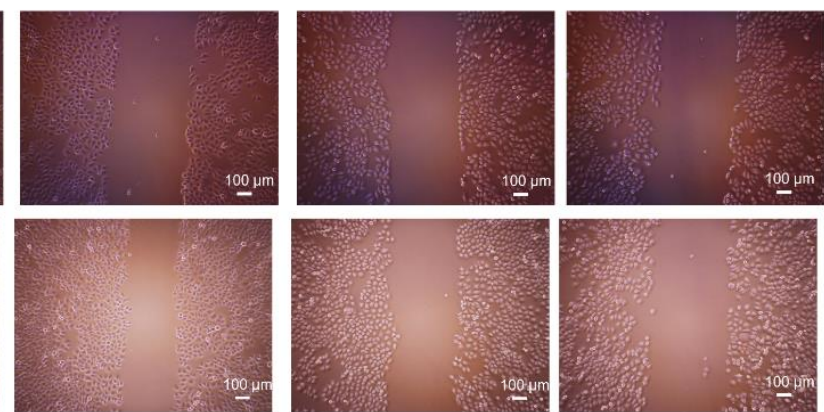

50

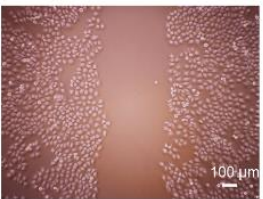

75

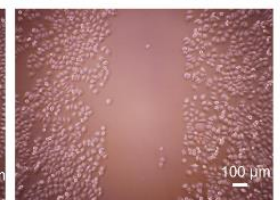

100

ALA $(\mu \mathrm{m})$

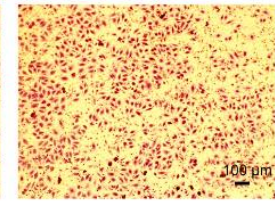

25

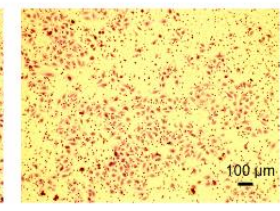

50

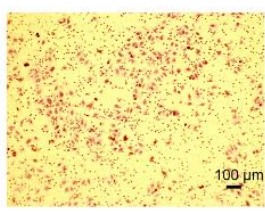

75

ALA $(\mu \mathrm{M})$
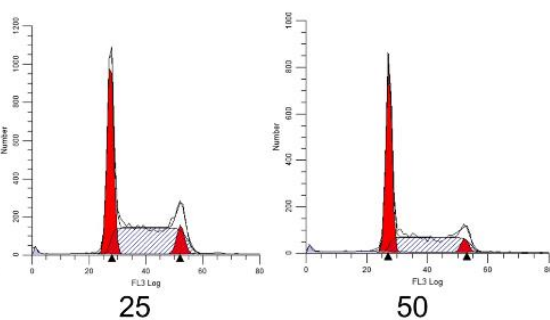

$\operatorname{ALA}(\mu \mathrm{M})$

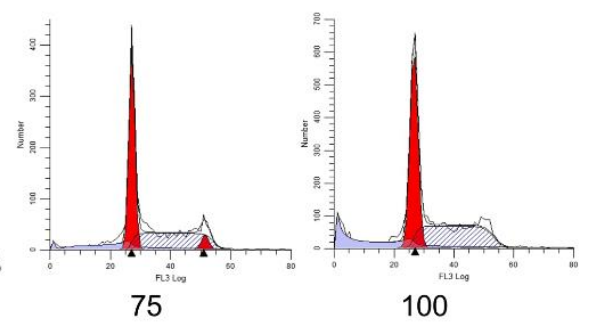

478

479

480

481

482

483

Figure 9. Effects of ALA on the FASN substrate.

Three substrates involved in the FASN reaction. MDA-MB-231 and MCF-7 cells were treated ALA (0, 25, 50, 75, and $100 \mu \mathrm{M}$ ) for $24 \mathrm{~h}$, corresponding kits (Acetyl-CoA kit, Malonyl-CoA kit, and NADPH kit) were used to measure acetyl-CoA, malonyl-CoA, and NADPH, respectively. ${ }^{*} \mathrm{p}<0.05,{ }^{*} \mathrm{p}<0.01$. 
MDA-MB-231
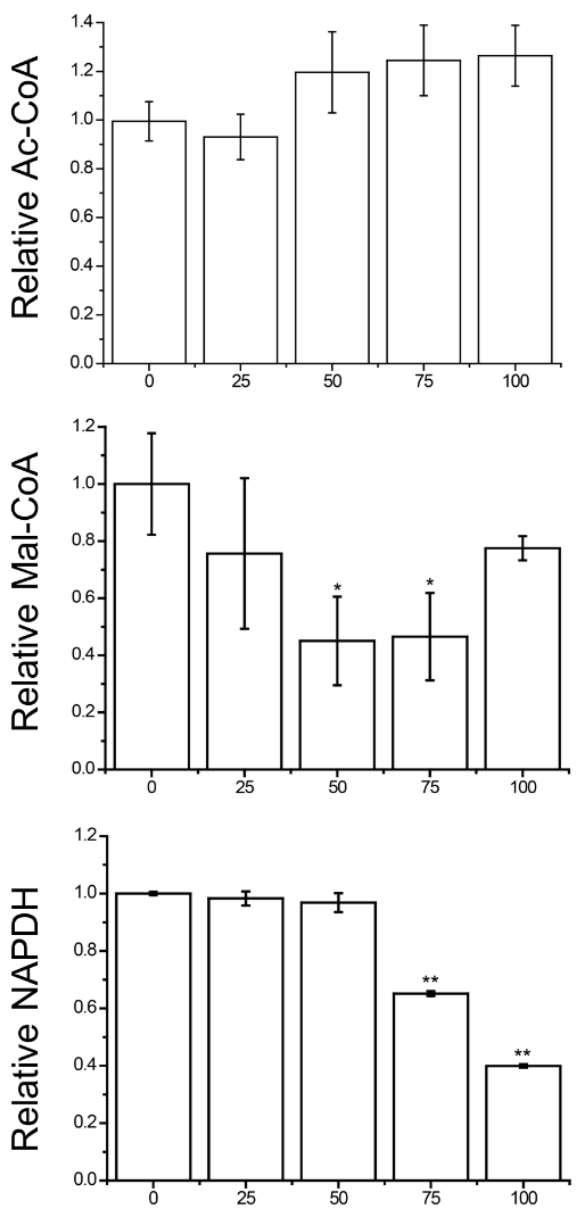

MCF-7
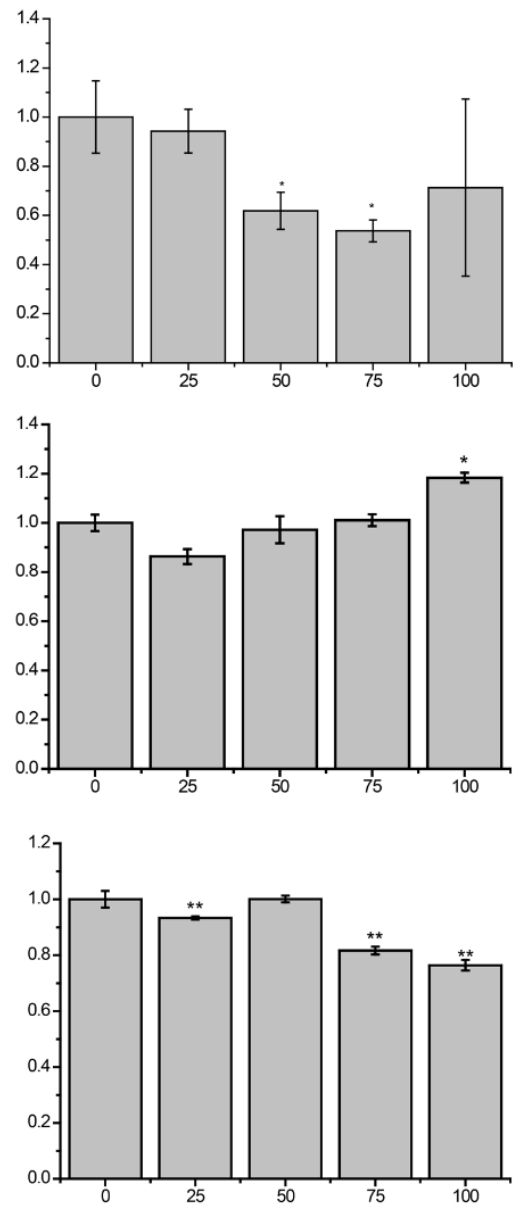

$\operatorname{ALA}(\mu \mathrm{M})$

Figure 10. Molecular docking for ALA and PA with TE domain of FASN.

(A) The distribution of binding energy for ALA with TE domain which calculated by Autodock Vina, the red shown in the figure D. (D) The binding model of PA with TE domain. 


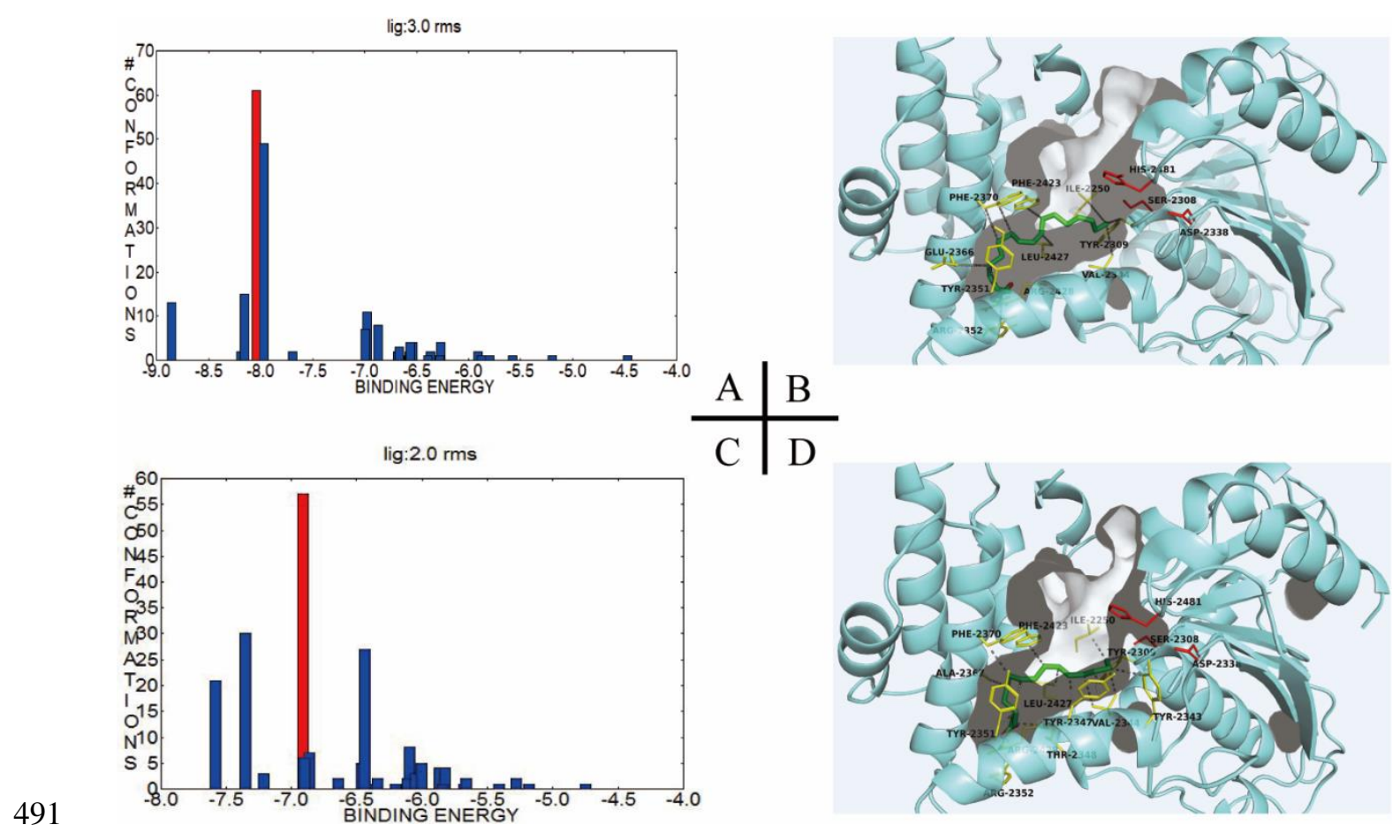


Figures

A

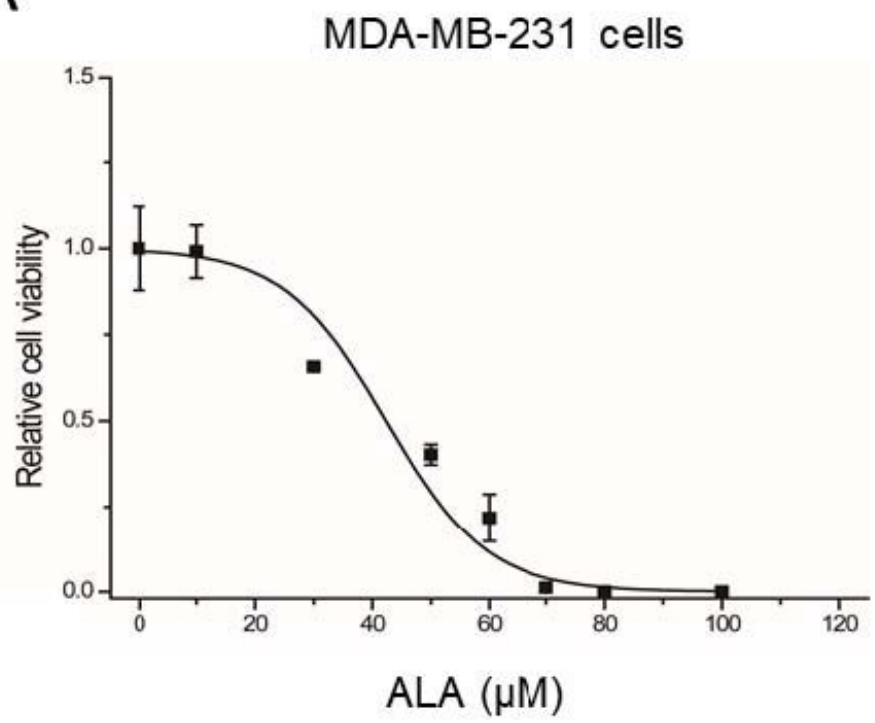

B

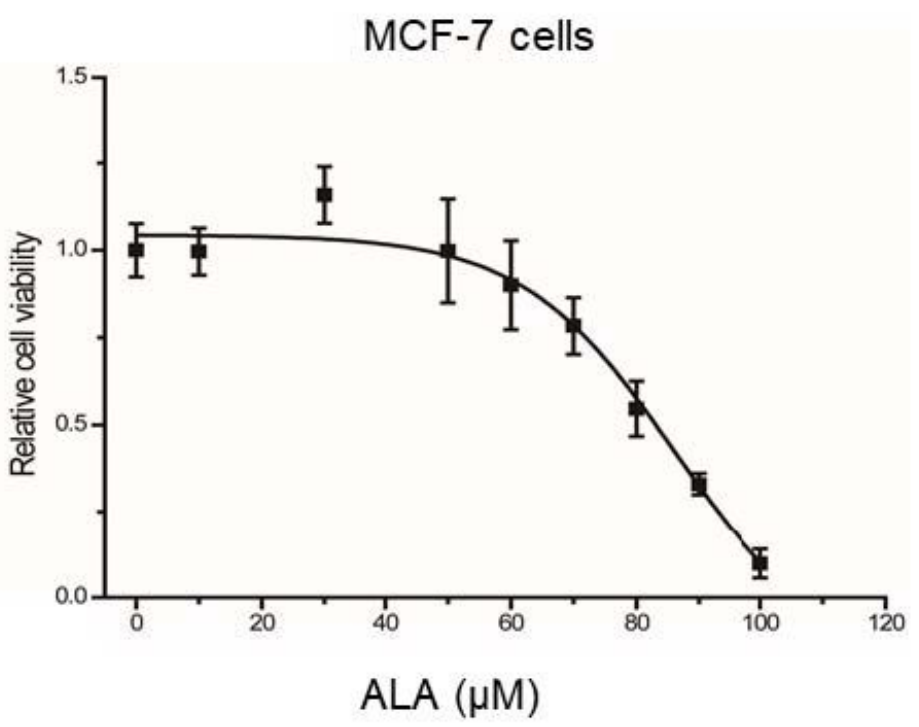

Figure 1

Effect of ALA on breast cancer cell viabilities. MDA-MB-231 cells (A) and MCF-7 cells (B) were treated by different concentrations of $\operatorname{ALA}(0,10,30,50,60,70,80,90$, and $100 \mu \mathrm{M})$ for $24 \mathrm{~h}$, cell viability was measured by MTT assay. Data represented the mean \pm SD of three independent experiments. MBA-MB231 cells. 
A
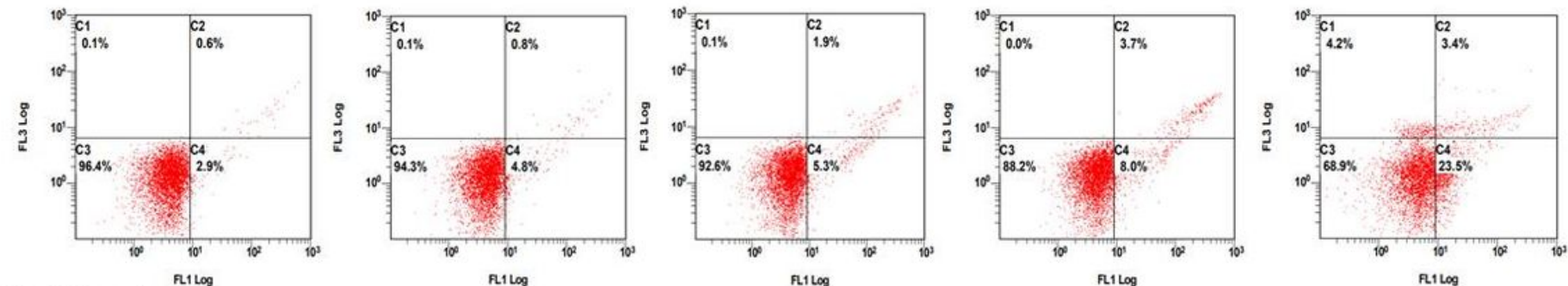

MDA-MB-231 cells

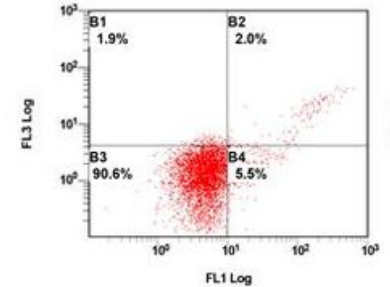

MCF-7 cells

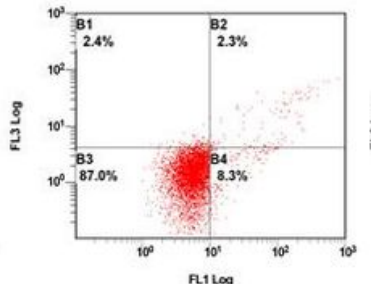

25

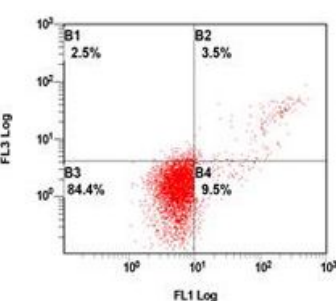

50

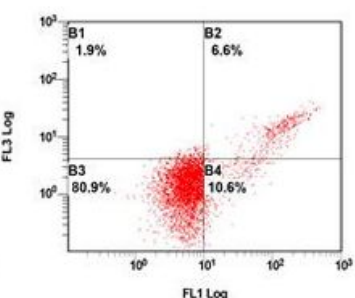

75

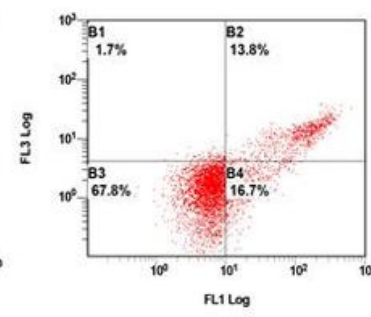

100 ALA $(\mu \mathrm{M})$

B

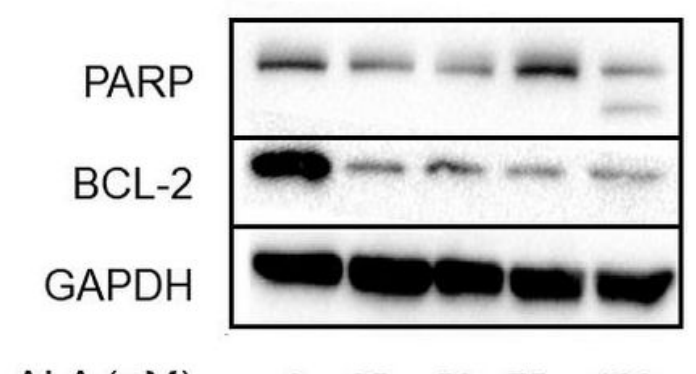

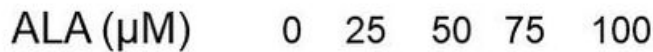

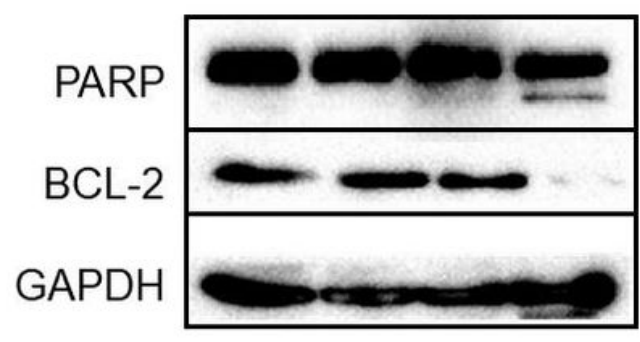

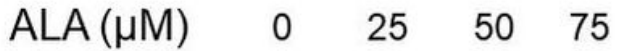

\section{Figure 2}

Apoptotic effect of ALA on MCF-7 and MDA-MB-231 cells. (A) MDA-MB-231 cells and MCF-7 cells were treated with various concentrations of ALA for $24 \mathrm{~h}$, then incubated and stained with annexin V/PI, analyzed by flow cytometry. (B) Apoptosis in MDA-MB-231 cells and MCF-7 cells was assessed by PARP cleavage and BCL-2 expression. GAPDH was chosen as a loading control. 
A MDA-MB-231 cells

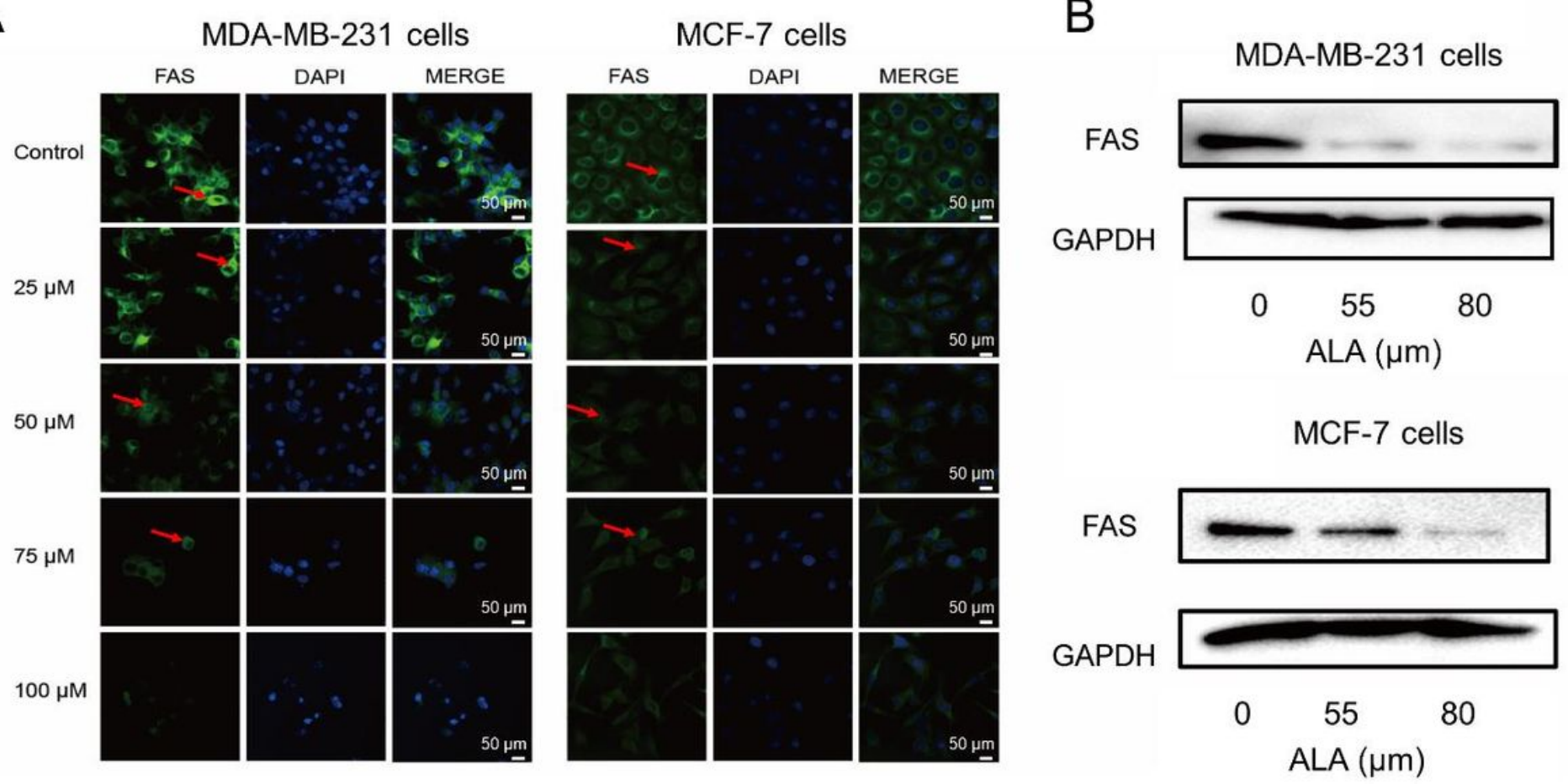

B

Figure 3

ALA down-regulated intercellular FASN expression in breast cancer cells. (A) The expression levels of FASN after ALA treatment for $24 \mathrm{~h}$ in MDA-MB-231 and MCF-7 cells were detected. FASN was stained by FASN antibody with FITC (green fluorescence), nucleus was stained by DAPI (blue fluorescence). The image was analyzed by fluorescence microscope. (B) The expression levels of FASN were analyzed by western blot after ALA treatment.

A

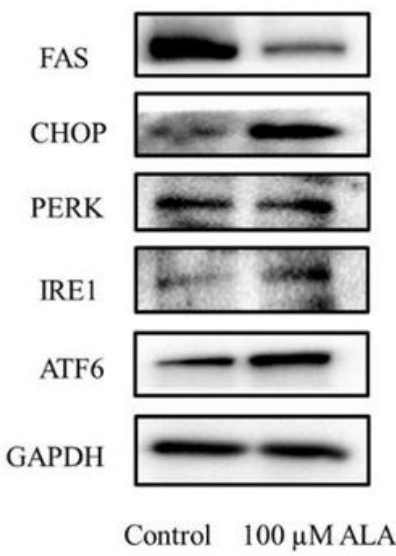

B
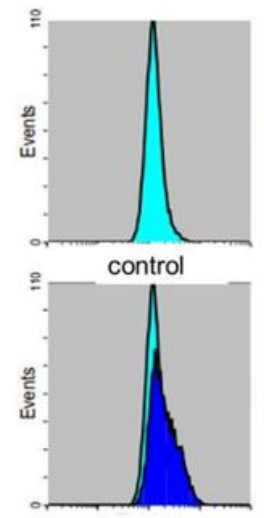

$75 \mu \mathrm{M}$
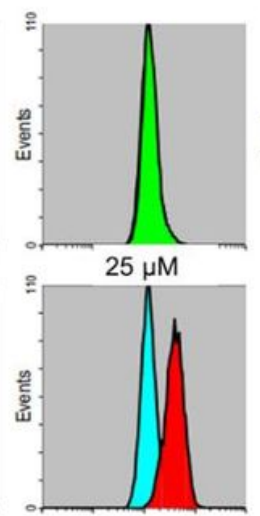

$100 \mu \mathrm{M}$

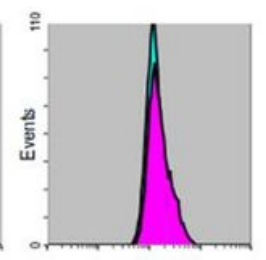

$50 \mu \mathrm{M}$
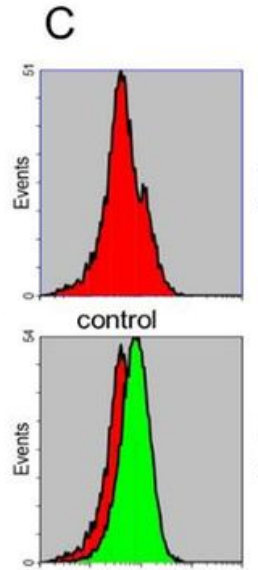

$75 \mu \mathrm{M}$

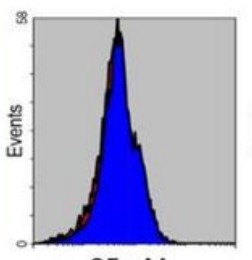

$25 \mu \mathrm{M}$

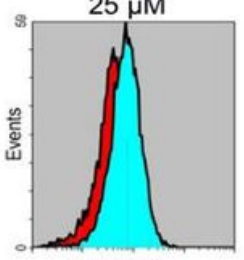

$100 \mu \mathrm{M}$

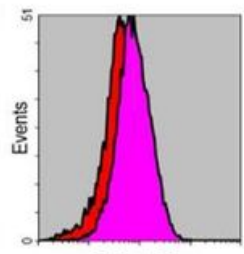

$50 \mu \mathrm{M}$

\section{Figure 4}

The effects of ALA on ER stress in MDA-MB-231 cells. (A) At $24 \mathrm{~h}$ after ALA $(100 \mu \mathrm{M})$ treatment, the relative expression levels of FASN, ATF6, IRE1, PERK, and CHOP were analyzed by western blot. (B) MDA- 
MB-231 cells and (C) MCF-7 cells were treated with $\operatorname{ALA}(0,25,50,75$, and $100 \mu \mathrm{M})$ analyzed by measuring the fluorescence shift of $\mathrm{JC}-1$ with a flow cytometer to assess the mitochondrial dysfunction.
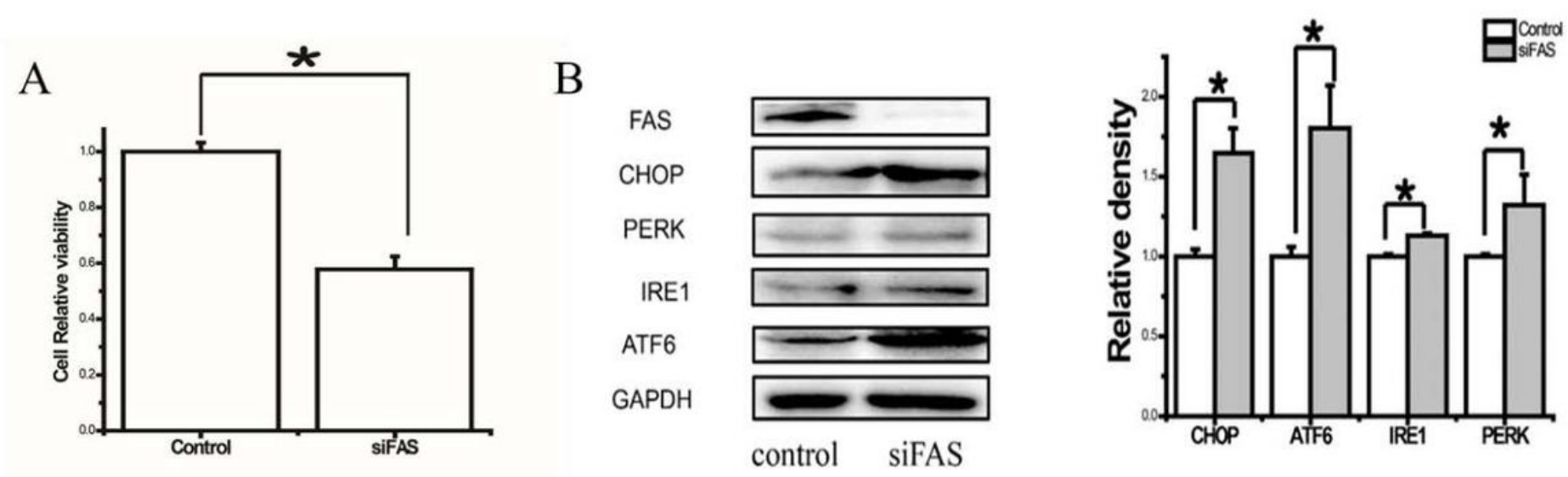

Figure 5

Down-regulating FASN expression reduced cell viability and induced ER stress in MDA-MB-457 231 cells. (A) MDA-MB-231 cells were transfected with FASN targeted siRNA for $24 \mathrm{~h}$. The survival rate of cells was measured by MTT assay. (B) The relative expression levels of ATF6, IRE1, PERK, and CHOP in MDA-MB231 cells were analyzed by Western blot. The density of proteins was quantified by ImageJ software. * $<$ 0.05 .

A

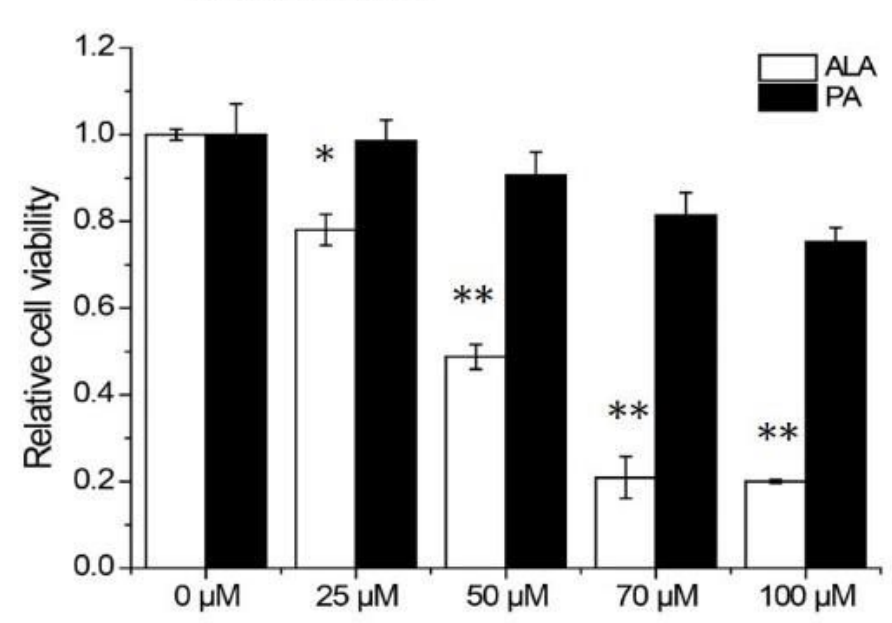

$\mathrm{C}$

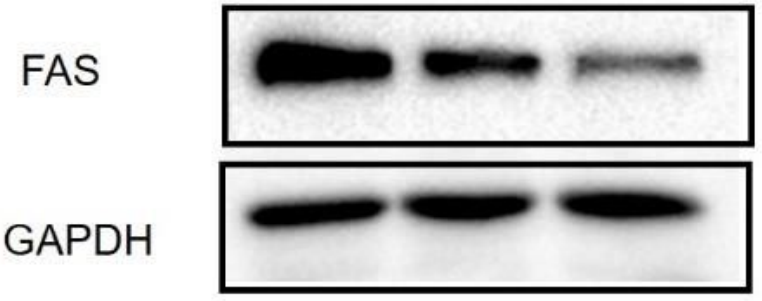

ALA $(\mu \mathrm{M}) \quad$ control $70 \quad 110$
B

MCF-7

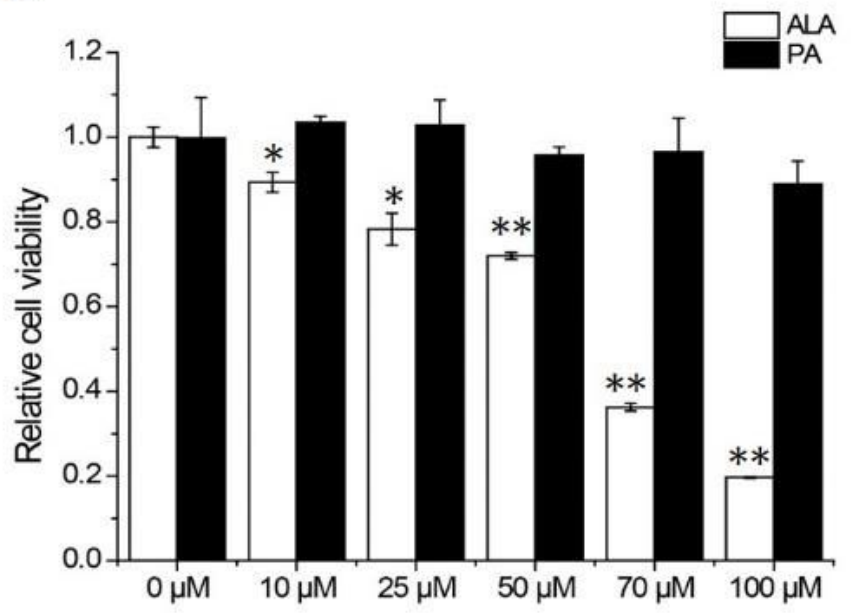

D

FAS

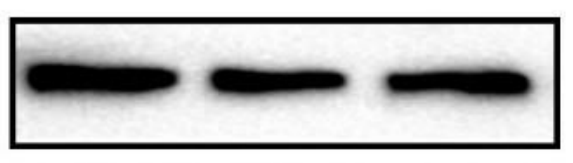

GAPDH

PA $(\mu \mathrm{M})$ control $70 \quad 110$ 
The effects of ALA, PA on cell viability and FASN expression level in breast cancer cells. Various concentration of ALA or PA $(0,25,50,70$, and $100 \mu \mathrm{M})$ treated MDA-MB-231 cells (A) and MCF-7 cells (B) for $24 \mathrm{~h}$, cell viabilities were measured by MTT assay. ${ }^{\star} \mathrm{p}<0.05,{ }^{\star \star} \mathrm{p}<0.01$. (C) and (D) FASN expression was analyzed by western blot after treating with ALA or PA for $24 \mathrm{~h}$.

MDA-MB-231 cells

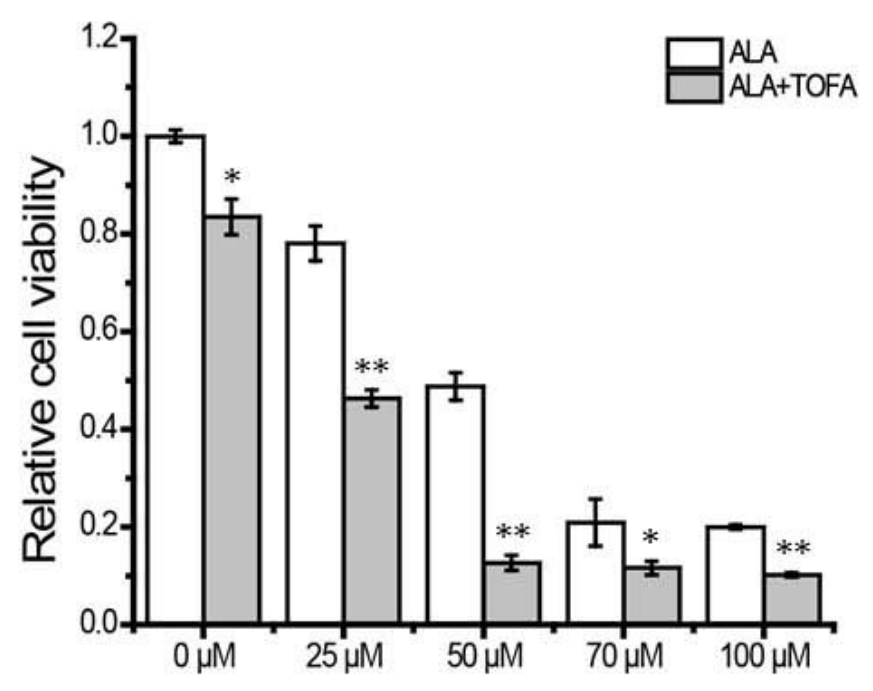

MCF-7 cells

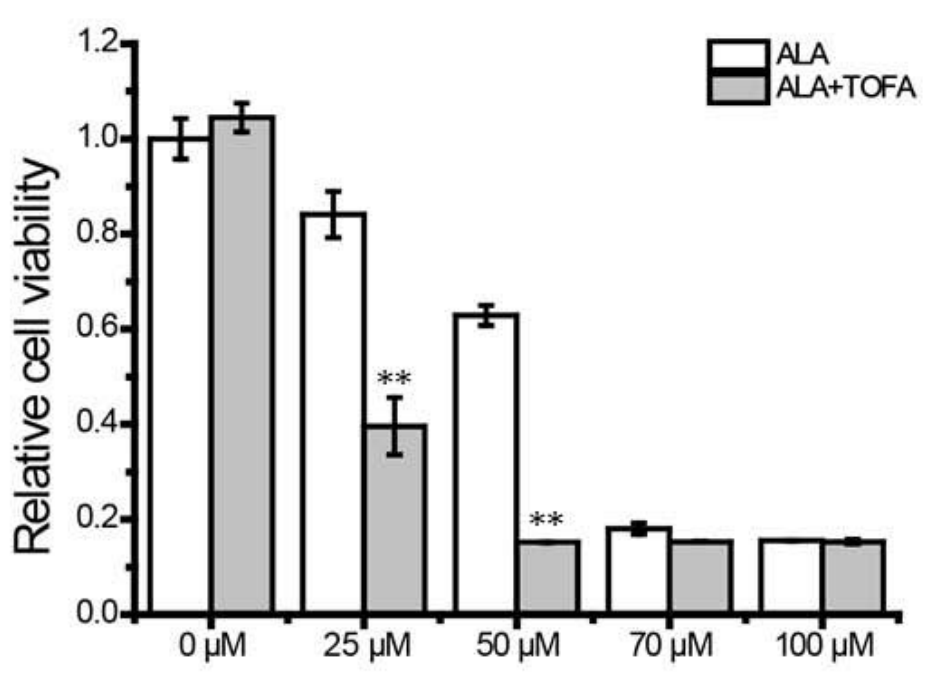

\section{Figure 7}

The effects of ALA and TOFA on cell viability in breast cancer cells. MDA-MB-231 cells and MCF-7 cells were treated with ALA alone or ALA accompany with TOFA for $24 \mathrm{~h}$, cell viabilities were measured by MTT assay. ${ }^{*} p<0.05,{ }^{*} p<0.01$. 

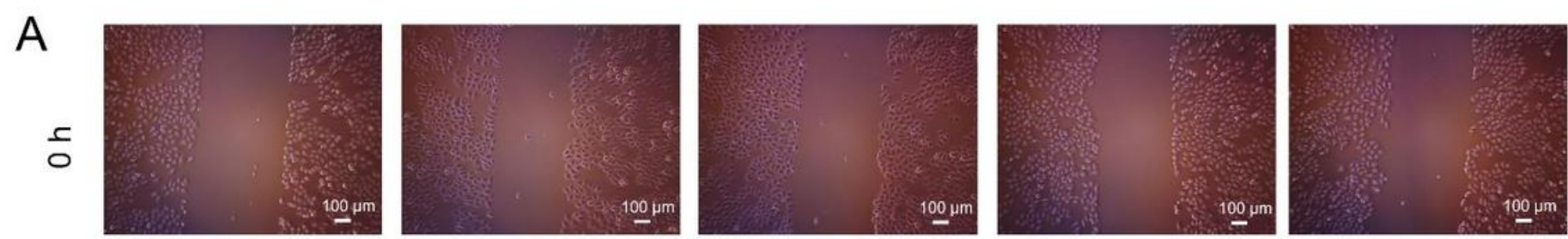

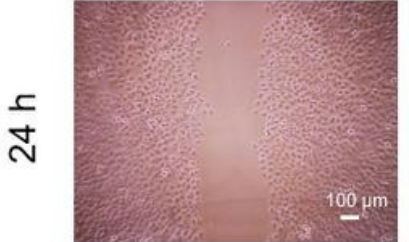

0

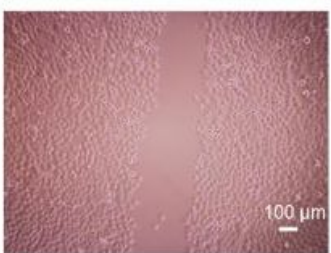

25

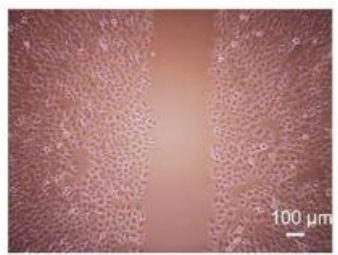

50

ALA $(\mu \mathrm{m})$

B

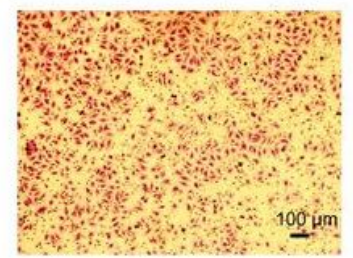

0
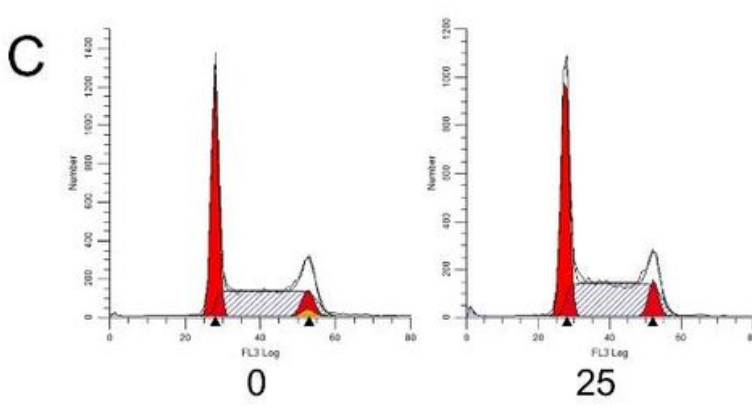

25

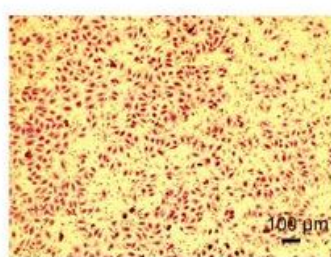

25

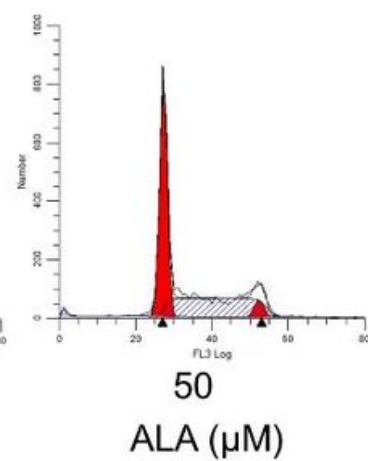

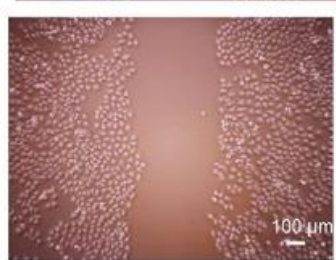

75

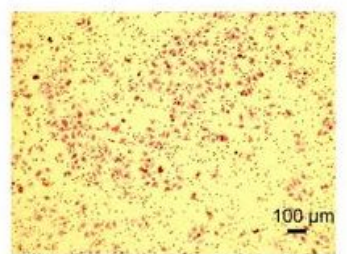

75

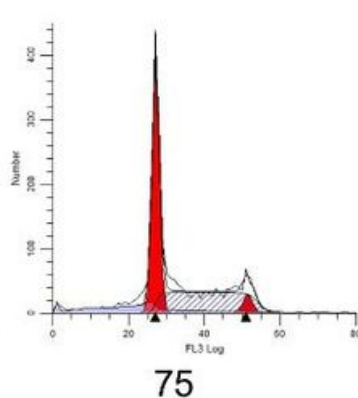

75

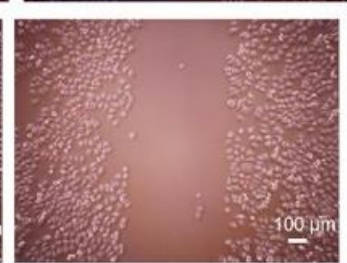

100

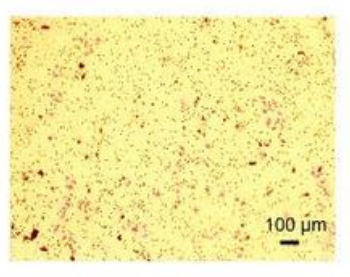

100

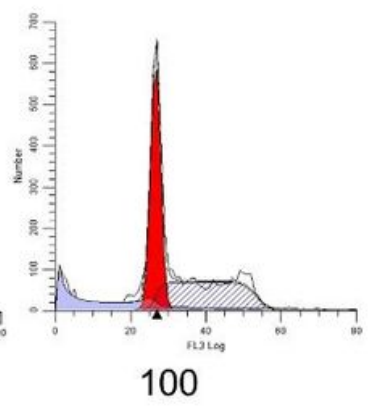

Figure 8

ALA inhibited the invasion and arrested the cell cycle of MDA-MB-231 cells. MDA-MB-231 cells were treated with $\operatorname{ALA}(0,25,50,75$, and $100 \mu \mathrm{M})$ for $24 \mathrm{~h}$. (A) Wound healing experiment. (B) Transwell assay. (C) Cell cycles were analyzed. 
MDA-MB-231
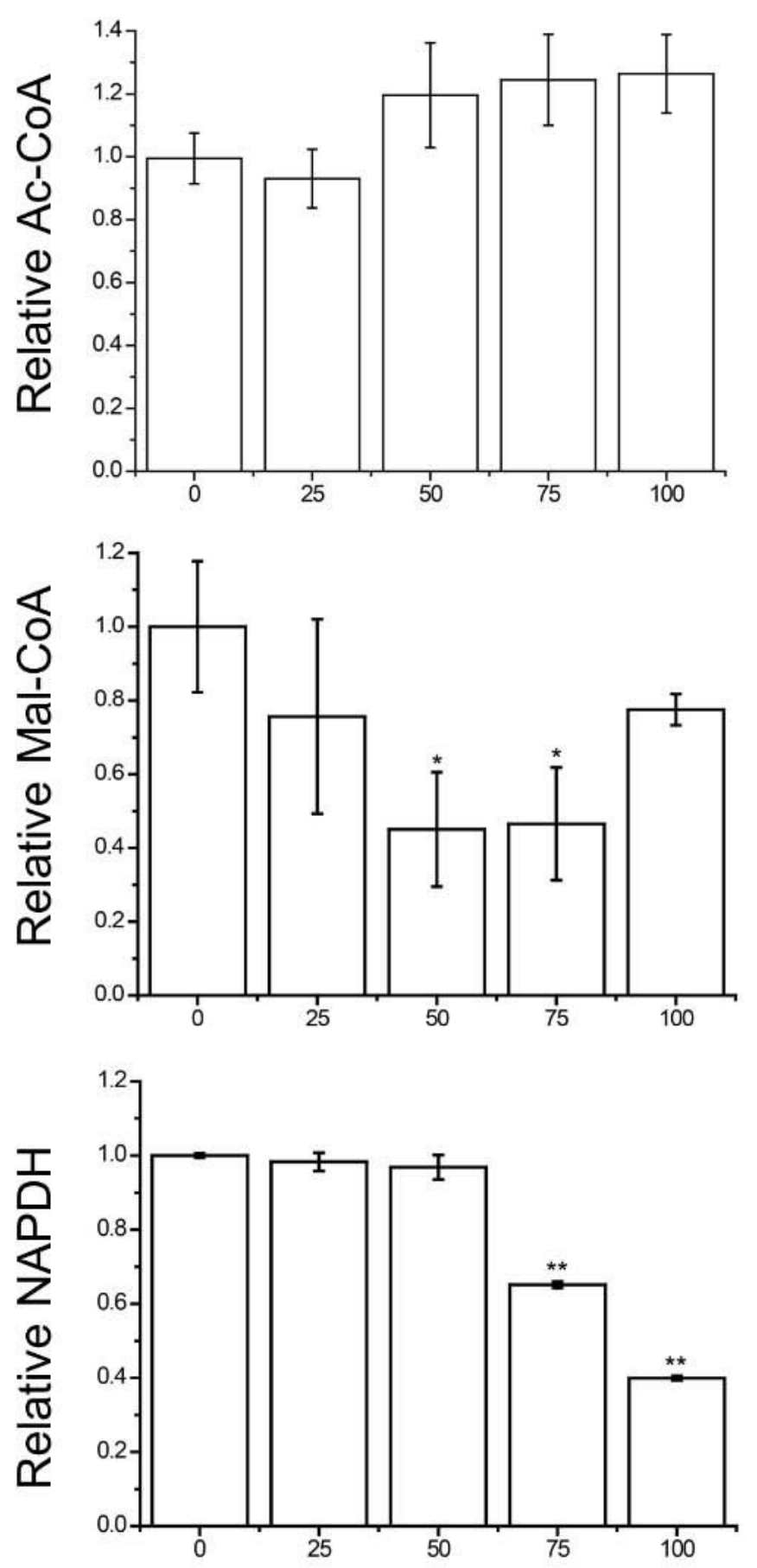

MCF-7
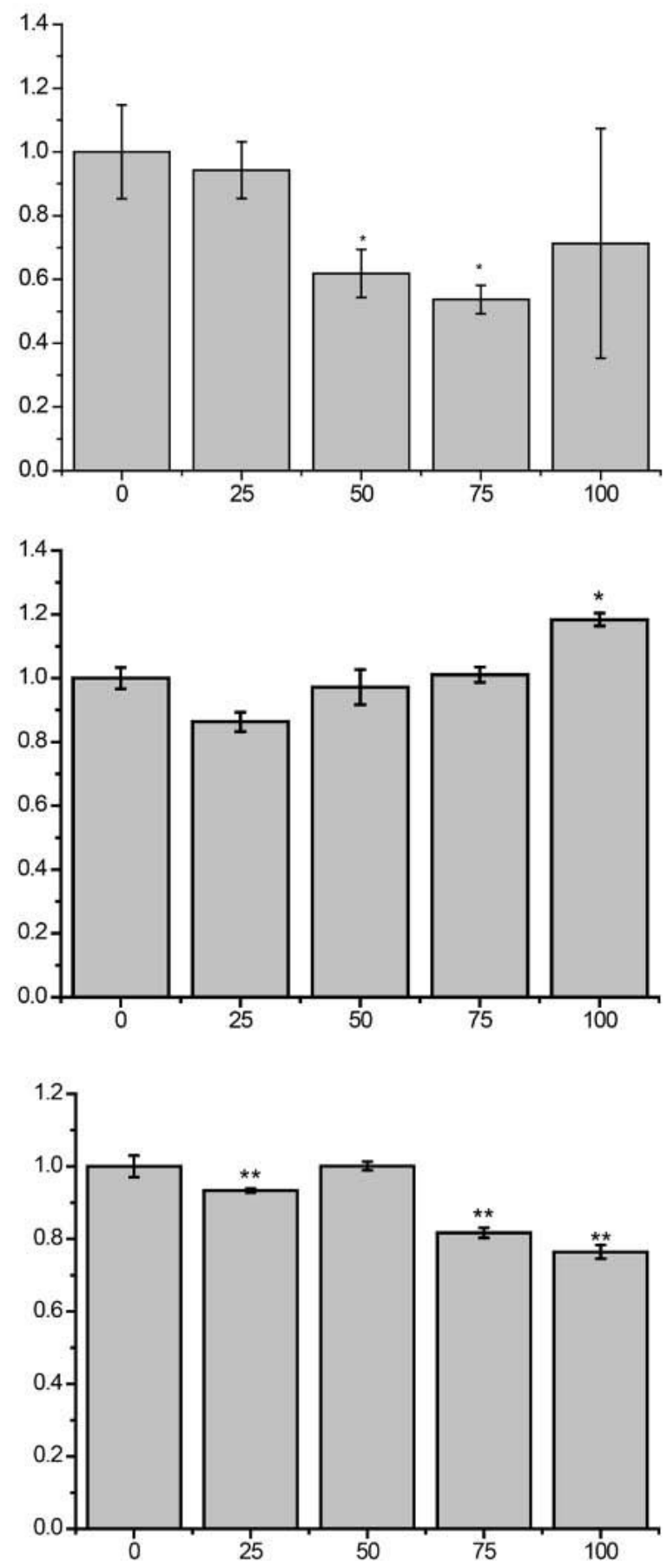

\section{ALA ( $\mu M)$}

\section{Figure 9}

Effects of ALA on the FASN substrate. Three substrates involved in the FASN reaction. MDA-MB-231 and MCF-7 cells were treated $\operatorname{ALA}(0,25,50,75$, and $100 \mu \mathrm{M})$ for $24 \mathrm{~h}$, corresponding kits (Acetyl-CoA kit, Malonyl-CoA kit, and NADPH kit) were used to measure acetyl-CoA, malonyl-CoA, and NADPH, respectively. ${ }^{*} p<0.05,{ }^{*} p<0.01$. 

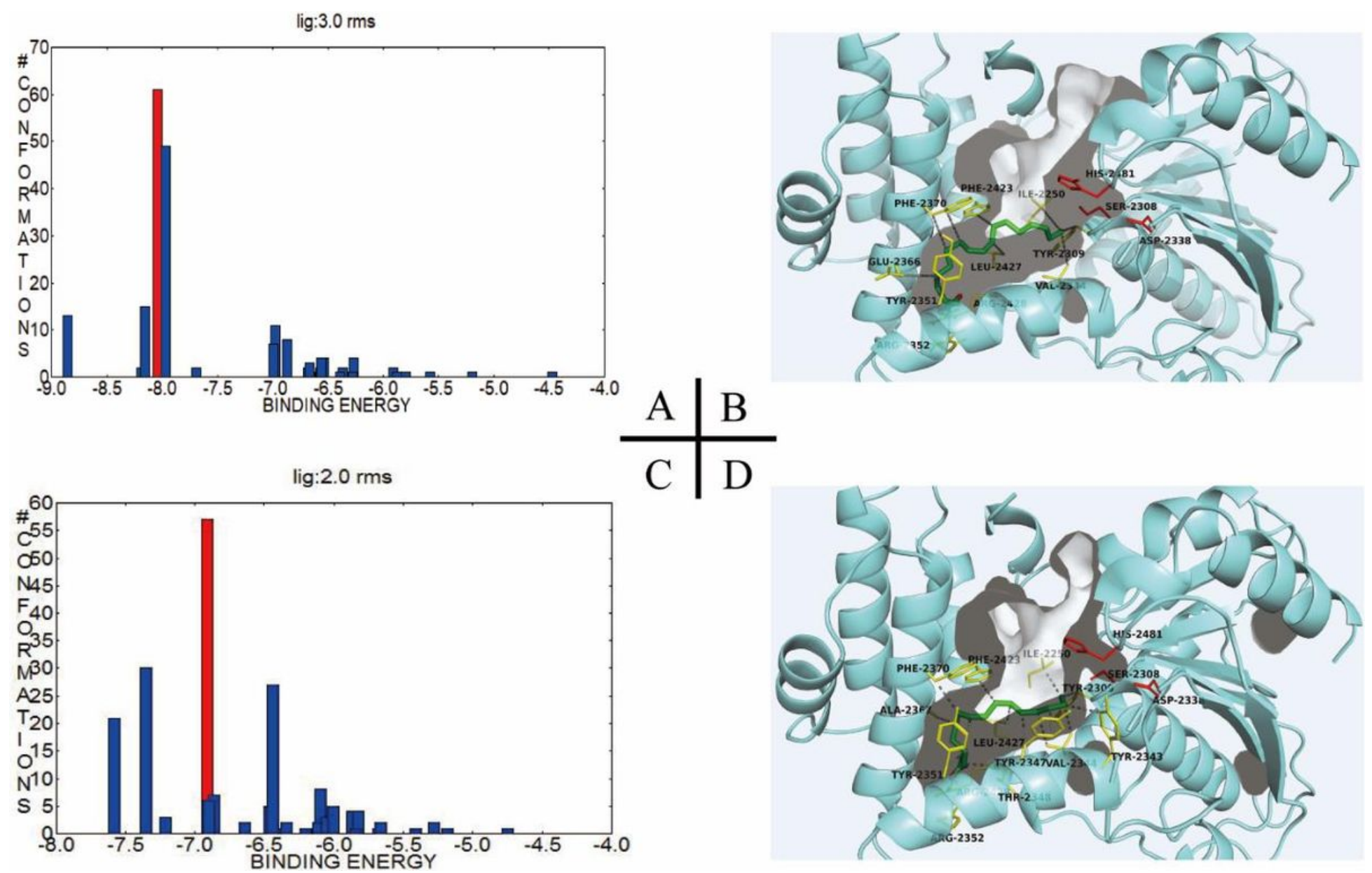

Figure 10

Molecular docking for ALA and PA with TE domain of FASN. (A) The distribution of binding energy for ALA with TE domain which calculated by Autodock Vina, the red column was analyzed by Pymol. (B) The binding model of ALA with TE domain. (C) The distribution of binding energy for PA with TE domain which calculated by Autodock Vina, the red column was analyzed by Pymol as shown in the figure D. (D) The binding model of PA with TE domain.

\section{Supplementary Files}

This is a list of supplementary files associated with this preprint. Click to download.

- Supplementaryoriginaldata.pdf 